\title{
Feasibility study on fixed flight-path angle descent for wide-body passenger aircraft
}

\author{
Eri Itoh $^{1}$ (D) Navinda K. Wickramasinghe ${ }^{1} \cdot$ Hiroko Hirabayashi $^{1} \cdot$ Sachiko Fukushima ${ }^{1}$
}

Received: 16 October 2017 / Revised: 15 August 2018 / Accepted: 17 October 2018 / Published online: 25 October 2018

(c) The Author(s) 2018

\begin{abstract}
This study proposes the use of fixed flight-path angle (FPA) descent as a potential alternative for eco-friendly air traffic operations. Additionally, given that the proposed descent procedure follows a fixed, assigned flight-path angle, with the aircraft continuously descending toward the runway threshold with near-idle thrust, the trajectory should be more predictable for air-traffic controllers. As such, the proposed approach is expected to contribute significantly toward decreasing the air traffic fuel consumption, while simultaneously facilitating the air traffic controllers' task of maintaining the required time spacing between concurrent traffic. Furthermore, FPA descent does not require any retrofits in the fundamental components of current ground systems and/or onboard avionics. This paper clarifies the feasibility of fixed flight-path angle descent for B777-200 and B787-8 wide-body jet passenger aircraft, envisaging its implementation in near-term operations. A total of 30 trials were carried out in a series of experiments designed to evaluate the proposed descent method, considering arrivals at two major international airports in Japan—the Tokyo and Kansai International Airports—using B777-200 and B787-800 full flight simulators of a national airline. The pilots' procedures, cockpit operability, assigned vertical path tracking performance, and fuel efficiency associated with the proposed FPA descent are discussed and compared with those of conventional arrival operations. The analysis results indicate that the fixed flight-path angle descent is feasible for large-sized jet aircraft within the assumed operational environment, and that its combined use with speed control has the potential to result in even better energy-saving performance in future air traffic management operations.
\end{abstract}

Keywords Air traffic management · Continuous descent operation · Flight simulator experiments $\cdot$ Fuel reduction · Asian economic growth

\section{Abbreviations \\ ATCo Air traffic controller \\ ATM Air traffic management \\ CAS Calibrated airspeed \\ CDO Continuous descent operation \\ CDU Control display unit}

Eri Itoh

eri@mpat.go.jp

Navinda K. Wickramasinghe

navinda@mpat.go.jp

Hiroko Hirabayashi

h-hirabayashi@mpat.go.jp

Sachiko Fukushima

sachiko@mpat.go.jp

1 Air Traffic Management Department, Electronic Navigation Research Institute, National Institute of Maritime, Port and Aviation Technology, 7-42-23 Jindaiji-Higashimachi, Chofu, Tokyo 182-0012, Japan
CI Cost index

ETA Estimated time of arrival

FAF Final approach fix

FIM Flight-deck interval management

FMC Flight management computer

FMS Flight management system

FPA Fixed flight-path angle

ISA International Standard Atmosphere

OPD Optimized profile descent

PD Profile descent

RTA Required time of arrival

TOD Top of descent

\section{Introduction}

Fuelled by the rapid economic growth in Asian countries, the demand for air travel in 2035 is forecasted to increase 2.5 times relative to 2015 [1]. Fuel-efficient arrival procedures 
have been extensively studied to mitigate environmental impacts and ensure eco-friendly airline operations, while simultaneously fostering punctuality in air traffic management (ATM). One of the solutions directly aiming at achieving fuel-saving arrivals is continuous descent operation (CDO) [2], in which the arriving aircraft descend to the airport continuously, using near-idle thrust. The ideal CDO is profile descent (PD), in which each aircraft follows an individual profile optimized by modern avionics systems, the flight management system (FMS). However, the unpredictability of aircraft trajectories-vertical profile, speed profile, position of the top of descent (TOD), etc.-during PD forces air traffic controllers (ATCos) to increase the safety separation intervals. Therefore, PD operations in the Japanese air space are currently only applicable in low-density air traffic situations. In [3], the authors proposed charted optimized profile descent (OPD) procedures, which consist of speed and altitude constraints on sets of a Standard Terminal Arrival Route (STAR) to the Los Angeles International Airport, and successfully reduced the stepdown vertical profiles in the terminal control area. To enhance the trajectory predictability and support the ATCos in estimating the hand-off aircraft altitude in en-route areas, this study suggests using fixed flight-path angle (FPA) descent, in which arriving aircraft descend continuously to the assigned runway following fixed vertical path angles. Using FPA descent does not require any retrofits in the fundamental components of the ground systems currently used for ATM. The pilot can easily share the assigned FPA values with the ATCo, therefore, the FPA descent strategy is expected to increase the predictability of the vertical trajectories from the ground.

Before discussing the implementation of FPA descent, two main questions must be clarified: the first is whether FPA descent is operationally feasible for pilots manipulating the FMS. The second is how much fuel could be saved by applying the proposed FPA descent, when compared to conventional operations. If the FPA approach is feasible from both points of view, then there is real potential in discussing FPA descent further, envisaging a possible near-term implementation.

Fixed flight-path angle descent has already been applied [4-6] to descent planning of small jet aircraft equipped with FMS, which have simpler vertical navigation capabilities than large commercial jet aircraft. Strategies for selecting a fuel-efficient and plausible FPA for small jet aircraft were discussed via simulation experiments designed to simulate arrivals at the John F. Kennedy and Dallas/Fort Worth International Airports. The obtained results indicated that the FPA descent was feasible, and that FPA selection was a key issue regarding the minimization of extra fuel burns. Fixed-flight path angle descent has been also studied for application in large commercial jet aircraft [7, 8]. A procedure to mitigate the impact of aircraft noise by maintaining a fixed lateral path and fixing the vertical path at $3^{\circ}$ was proposed in [7]. Given that this procedure includes a phase of idle descent, it limits the controllable speed range (by thrust control) for maintaining traffic separation. A new procedure using variable FPA has also been proposed to control arrival time [8]. This procedure was evaluated via human-inthe-loop simulation experiments simulating a pilot's arrival into the Schiphol Airport, in The Netherlands. These results show that the allowed FPA variability enables the possibility of adjusting the estimated time of arrival (ETA) to approach the required time of arrival (RTA). In previous studies by the authors [9-11], speed control was combined with FPA descent to ensure the desired time spacing in the arrival traffic. Automatic speed control by aircraft self-separationflight-deck interval management (FIM) [12, 13] —was applied to FPA descent of domestic flights arriving at the Tokyo International Airport from the western part of Japan. The preliminary results obtained via Monte Carlo simulations indicate that the combination of aircraft speed control and FPA descent attains the required time spacing performance, while reducing the fuel consumption of the arrival traffic [9-11]. Flight-deck interval management evaluation was completed in NASA's ATD-1 project [14, 15]; however, FPA descent has not been used in their human-in-the-loop simulations.

This study aims at advancing the feasibility studies on FPA descent for wide-body passenger aircraft, and simultaneously reviewing arrival operations combining speed control with FPA descent, via full flight simulator experiments. A series of experiments were carried out using B777-200 and B787-800 full flight simulators, with the collaboration of a national airline company, during the April 2014-March 2016 period. In $[11,16]$, some of the experimental results obtained using the B777-200 full flight simulator (a total of 11 trials) were preliminarily analyzed, to discuss the operational feasibility and fuel efficiency of FPA descent targeting arrivals at the Tokyo International Airport. In line with previous work, this paper advances the FPA feasibility studies through successive experiments (a total of 30 trials) of arrivals at the Tokyo International Airport and the Kansai International Airport, using B777-200 and B787-800 full flight simulators. Four airline pilots were involved in the trials. Although the number of experiments is not sufficient to analyze the effect of individual pilot behaviors on the data, these experiments are valuable to indicate general trends in the feasibility of the proposed FPA descent strategy. Based on the experimentally obtained results, the environmental benefits of implementing the proposed approach are discussed by comparing them with both PD and conventional arrival operations.

This paper is organized as follows. Section 2 describes the experimental environment and procedures to simulate the FPA descent using the B777-200 and B787-800 full 
flight simulators. Section 3 verifies the vertical PD profiles and controls for different airports and runways, following six different arrival routes, under two seasonal wind conditions. Section 4 evaluates the pilots' procedures and cockpit operability, the assigned vertical path tracking performance, and the fuel efficiency during FPA descent. Section 5 compares the FPA descent vertical profiles with those of PD when aircraft speed control is combined to absorb the arrival delay in air traffic. Section 6 discusses the fuel efficiency of FPA descent and its combination with aircraft speed control by comparison with conventional arrival operations (including radar vectoring, early descent, RTA operation, and partial PD). Section 7 discusses the novelties of this study as compared with conventional studies on CDO. It also discusses planned future work aimed at implementing FPA descent into ATM systems. Section 8 concludes this paper.

\section{Full flight simulator experiments}

\subsection{Full flight simulators}

A series of flight simulator experiments were performed in March 2016, involving a total of 30 trials targeting the Tokyo and Kansai International Airports, using B777-200 and B787-800 full flight simulators, as shown in Fig. 1. Both simulators are fully certified for pilot training. In total, four pilots participated in the experiments, all of them operational airline pilots; one was a B787 pilot and the others were B777 pilots. The first B777 pilot was a captain with $5746 \mathrm{~h}$ of experience in the B777 and previously served as crew on B747-400 and MD11 aircraft. The second B777 pilot was a captain with $5879 \mathrm{~h}$ of experience on the B777 and previously served as a crew on B767 aircraft. The third B777 pilot was a co-pilot with $1434 \mathrm{~h}$ of experience in the B777 and previously served as a crew on B747-400 aircraft. The B787 pilot was a co-pilot with $1860 \mathrm{~h}$ of experience in the B787 and previously served as a crew on B777 aircraft. There was only one pilot in the simulator at each trial. Tables 1 and 2 summarize the flight scenarios used in the trials. A total of 25 trials simulated CDO including PD, FPA descent, and speed control during PD and FPA descent, as summarized in Table 1; a total of five trials simulated conventional arrival operations covering early descent, radar vectoring, partial PD, and the ATCo's request to delay the arrival using the RTA function of the FMS, as summarized in Table 2. Six different arrival routes were used in the experiments, as explained in the next section.

\subsection{Route settings}

Figure 2 shows the six arrival routes selected for the experiments. Three of these arrival routes correspond to arrivals
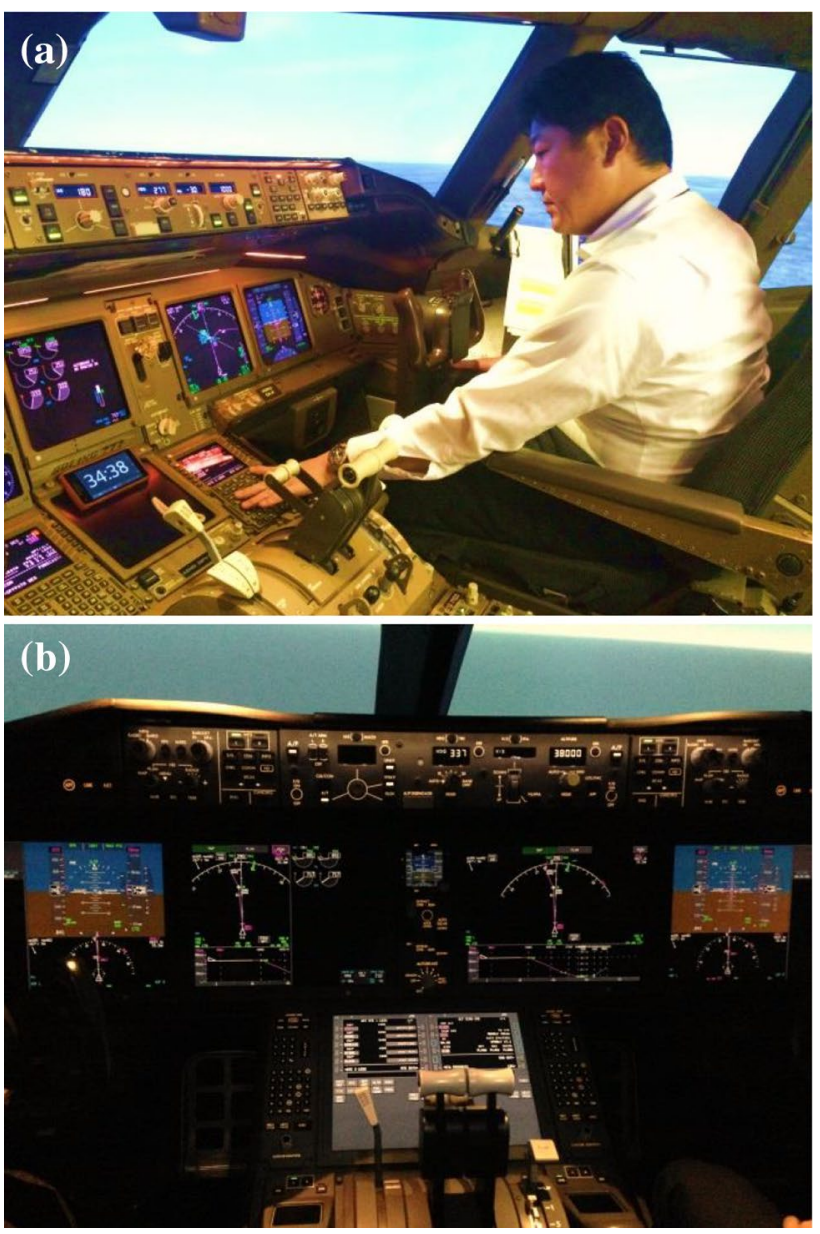

Fig. 1 B777-200 and B787-800 full-flight simulators. a Pilot inputting arrival route information into the CDU of the B777-200 fullflight simulator. b Displays and controls of the B787-800 full-flight simulator

at the Tokyo International Airport via oceanic air routes: "SMOLT via KAIHO to ILS Y RWY34L", "SMOLT via ARLON to ILS Z RWY34L", and "SMOLT via BACON to LDA W RWY22". Waypoint SMOLT, located close to the $143^{\circ} \mathrm{E}$ meridian, is the starting point of these arrival routes. The other three routes correspond to arrivals at runway $24 \mathrm{R}$ (RWY24R) of the Kansai International Airport from three different starting points (MADOG, SALTY, and CHILY): "MADOG via KARIN to ILS Y RWY24R", "SALTY via RANDY to ILS Y RWY24R", and "CHILY via SAEKI to ILS Y RWY24R". The set of waypoints and the distances between them on each route [17] are summarized in Table 3.

\subsection{Wind conditions}

Two types of wind condition sets were selected, based on the global spectral model in [18]. The first selected set of wind data was obtained in winter conditions; the data were observed at 12 UTC and estimated at 00 UTC 
Table 1 CDO Trials

\begin{tabular}{|c|c|c|c|c|c|}
\hline No. & Trial ID & Aircraft type & $\begin{array}{l}\text { Initial } \\
\text { cruise } \\
\text { altitude }\end{array}$ & Airport & Arrival route/RUNWAY \\
\hline \multicolumn{6}{|c|}{$P D(7$ trials $)$} \\
\hline 1 & PD-KH1 & B777 & FL380 & RJTT & SMOLT via KAIHO to ILS Y RWY34L \\
\hline 2 & PD-AR & B777 & FL380 & RJTT & SMOLT via ARLON to ILS Z $\underline{\text { RWY34L }}$ \\
\hline 3 & PD-BA & B777 & FL380 & RJTT & SMOLT via BACON to LDA W $\underline{\text { RWY22 }}$ \\
\hline 4 & PD-KR & B777 & FL390 & RJBB & MADOG via KARIN to ILS Y RWY24R \\
\hline 5 & PD-RA & B777 & FL350 & RJBB & SALTY via RANDY to ILS Y $\underline{\text { RWY24R }}$ \\
\hline 6 & PD-SA & B777 & FL360 & RJBB & CHILY via SAEKI to ILS Y $\underline{\text { RWY24R }}$ \\
\hline 7 & PD-KH2 & B787 & FL380 & RJTT & SMOLT via KAIHO to ILS Y RWY34L \\
\hline \multicolumn{6}{|c|}{ FPA descent (12 trials) } \\
\hline 8 & FPA-AR-35-30 & B777 & FL380 & RJTT & SMOLT via ARLON to ILS Z $\underline{\text { RWY34L }}$ \\
\hline 9 & FPA-AR-30-25 & B777 & FL380 & RJTT & SMOLT via ARLON to ILS Z RWY34L \\
\hline 10 & FPA-AR-30-22 & B777 & FL380 & RJTT & SMOLT via ARLON to ILS Z $\underline{\text { RWY34L }}$ \\
\hline 11 & FPA-AR-25-22 & B777 & FL380 & RJTT & SMOLT via ARLON to ILS Z $\underline{\text { RWY34L }}$ \\
\hline 12 & FPA-BA-30-27 & B777 & FL380 & RJTT & SMOLT via BACON to LDA W $\underline{\text { RWY22 }}$ \\
\hline 13 & FPA-BA-27-25 & B777 & FL380 & RJTT & SMOLT via BACON to LDA W $\underline{\mathrm{RWY} 22}$ \\
\hline 14 & FPA-BA-25-22 & B777 & FL380 & RJTT & SMOLT via BACON to LDA W $\underline{\text { RWY22 }}$ \\
\hline 15 & FPA-KR-30 & B777 & FL390 & RJBB & MADOG via KARIN to ILS Y $\underline{\text { RWY24R }}$ \\
\hline 16 & FPA-KR-25 & B777 & FL390 & RJBB & MADOG via KARIN to ILS Y RWY24R \\
\hline 17 & FPA-KR-22 & B777 & FL390 & RJBB & MADOG via KARIN to ILS Y $\underline{\text { RWY24R }}$ \\
\hline 18 & FPA-KH2-27-22 & B787 & FL380 & RJTT & SMOLT via KAIHO to ILS Y RWY34L \\
\hline 19 & FPA-KH2-22-20 & B787 & FL380 & RJTT & SMOLT via KAIHO to ILS Y RWY34L \\
\hline \multicolumn{6}{|c|}{ PD with speed control (2 trials) } \\
\hline 20 & PDS-KR & B777 & FL390 & RJBB & MADOG via KARIN to ILS Y RWY24R \\
\hline 21 & PDS-KH2 & B787 & FL380 & RJTT & SMOLT via KAIHO to ILS Y RWY34L \\
\hline \multicolumn{6}{|c|}{ FPA descent with speed control (4 trials) } \\
\hline 22 & FPAS-AR-25-22 & B777 & FL380 & RJTT & SMOLT via ARLON to ILS Z RWY34L \\
\hline 23 & FPAS-BA-25-22 & B777 & FL380 & RJTT & SMOLT via BACON to LDA W $\underline{\text { RWY22 }}$ \\
\hline 24 & FPAS-KR-22 & B777 & FL390 & RJBB & MADOG via KARIN to ILS Y $\underline{\text { RWY24R }}$ \\
\hline 25 & FPAS-KH2-22-20 & B787 & FL380 & RJTT & SMOLT via KAIHO to ILS Y RWY34L \\
\hline
\end{tabular}

Table 2 Trials to simulate conventional arrival operation

\begin{tabular}{lllllll}
\hline No. & Trial name & Aircraft type & Initial cruise altitude & Airport & Arrival route/Runway & Operation \\
\hline 26 & DES-KR & B777 & FL390 & RJBB & MIDAI via MADOG, KARIN to ILS Y RWY24R & Early descent \\
27 & RTA-KR & & & & RTA operation \\
28 & RV1-KR & & & Radar vector \\
29 & PDC-KR & & & Cancelled PD \\
30 & PDA-KR & & & Conditional PD \\
\hline
\end{tabular}

(12 $\mathrm{h}$ prior to the observation) on November 8, 2013. The second set was obtained in summer conditions; the data were observed at 12 UTC and estimated at 06 UTC $(6 \mathrm{~h}$ prior to the observation) on July 17, 2015. Four layers of the estimated wind data sets, including wind speed, direction, altitude, and corresponding waypoints at the estimated positions were input by the pilots into the flight management computer (FMC) before each flight, as per Table 4. Other four layers of the actual wind datasets, including wind speed, direction, and altitude, were input into the computer system operating the flight simulators, as per Table 5 . The set of winter wind was used in the trials arriving at runway $34 \mathrm{~L}$ of the Tokyo International Airport. The set of summer wind was used with runway 22 of the Tokyo International Airport and runway 24R of the Kansai International Airport. The International Standard Atmosphere (ISA) model was assumed in all experiments. 

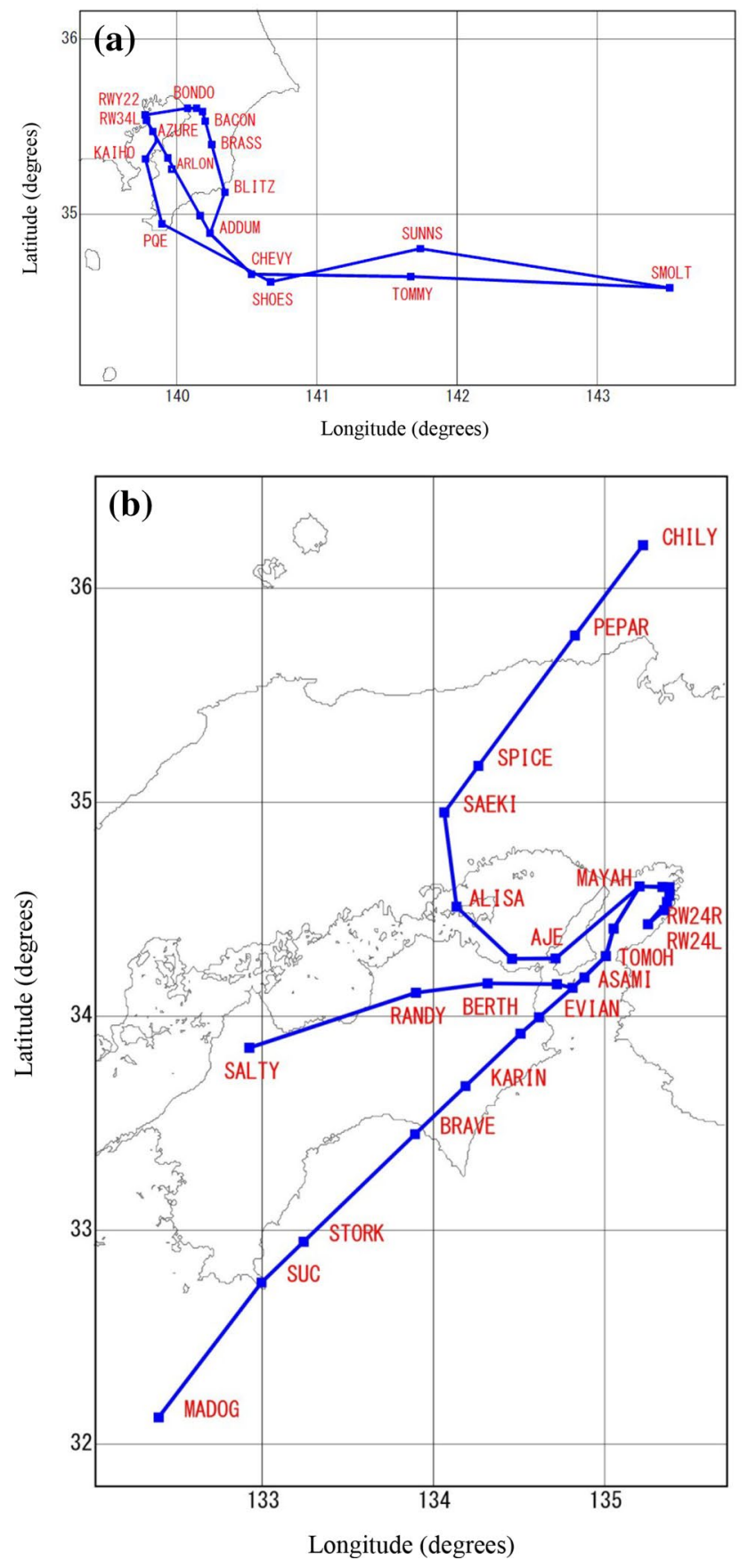

Fig. 2 Six considered arrival routes. a Tokyo International Airport. b Kansai International Airport

\subsection{Fixed flight-path angle selection}

The selection of FPA values depends on aircraft performance, FMS parameter settings, the cost index (CI) values chosen by the airlines, wind effects, and the deviation between the actual and estimated wind velocity and directions. First, the feasible FPA values were estimated based on fast-time simulation using aircraft performance models [19].
Although the kinematic aircraft behavior could be analyzed via the numerical simulation, the aircraft behavior simulating precision was low because it could not consider the CIrelated economical aircraft speed (ECON speed), the FMS parameter settings, the pilots' control of speed brake, or the pilot's capability to operate. Therefore, as a second step, the more plausible FPA values were confirmed via high-fidelity simulation using full-flight simulators: the pilots carried out the PD trials on each scenario shown in Table 1, and the plausible sets of FPA values for B777-200 and B787-800 aircraft were then determined through discussions with the pilots, referring to the profiles of flight-path angles observed during the PD trials on each route and under each set of wind conditions. One pilot was assigned to each trial and he expressed his opinion, based on his experiences during the trial. Table 6 summarizes the FPA values selected for the FPA descent simulation experiments.

\subsection{Operational procedures}

Pilots are required to operate the FMC to let the autopilot follow the assigned FPA vertical path. However, the FMCs with which both B777-200 and B787-800 full flight simulators are equipped do not possess a function to directly input FPA values. Therefore, to perform the FPA descent, the pilots initially created new waypoints on the planned horizontal path using the control display unit (CDU), and then altitude constraints were input at the corresponding waypoints. It was assumed that the aircraft would follow the desired vertical path by continuously enforcing the altitude constraints; in fact, the FPA descent could thus be carried out in accordance with the assigned FPA vertical path. The FPA descent terminated at the final approach fix (FAF).

Table 7 summarizes the pilot inputs to the FMC (via the CDU) that were applied in the four trials of FPA descent for "SMOLT via ARLON to ILS Z RWY34L". For instance, in the case of the FPA-AR-35-30 trial, the pilot created a new waypoint (CHV02) $40 \mathrm{NM}$ before the CHEVY waypoint via the CDU. The cruise altitude FL380 was input to the SMOLT and TOMMY waypoints, and altitude constraints were enforced at the CHV02 and ADDUM waypoints. An altitude of $5000 \mathrm{ft}$ was defined for the APOLO waypoint (FAF), as initially defined in the FMC. The altitude constraints were prepared in advance to define the FPA sets shown in Table 6.

During the FPA trials, ECON speed was used and the VNAV/PATH mode was active, so that the assigned vertical path with altitude constraints was followed. In the PD trials, the pilots input the cruise altitude at the first waypoint via CDU. ECON speed was defined for the entire flight profile. Speed restrictions ( $250 \mathrm{kn}$ at $10,000 \mathrm{ft}$, plus the FAF restrictions) were set in the FMC for all the trials. 
Table 3 Waypoint sets and path length following the six arrival routes

\begin{tabular}{|c|c|c|c|c|c|c|}
\hline \multirow{2}{*}{$\begin{array}{l}\text { Way- } \\
\text { point } \\
\text { number }\end{array}$} & \multicolumn{6}{|c|}{ Waypoint name (distance to the next waypoint; NM) } \\
\hline & $\begin{array}{l}\text { SMOLT via KAIHO } \\
\text { to ILS Y RWY34L }\end{array}$ & $\begin{array}{l}\text { SMOLT via } \\
\text { ARLON to ILS Z } \\
\underline{\text { RWY34L }}\end{array}$ & $\begin{array}{l}\text { SMOLT via BACON } \\
\text { to LDA W } \underline{\text { RWY22 }}\end{array}$ & $\begin{array}{l}\text { MADOG via } \\
\text { KARIN to ILS Y } \\
\underline{\text { RWY24R }}\end{array}$ & $\begin{array}{l}\text { SALTY via RANDY } \\
\text { to ILS Y RWY24R }\end{array}$ & $\begin{array}{l}\text { CHILY via SAEKI } \\
\text { to ILS Y RWY24R }\end{array}$ \\
\hline 1 & SMOLT (89) & SMOLT (92) & SMOLT (92) & MADOG (49) & SALTY (51) & CHILY (32) \\
\hline 2 & SUNNS (55) & TOMMY (56) & TOMMY (56) & SUC (17) & RANDY (21) & PEPAR (46) \\
\hline 3 & SHOES (42) & CHEVY (20) & CHEVY (20) & STORK (44) & BERTH (20) & SPICE (16) \\
\hline 4 & PQE (23) & ADDUM (7) & ADDUM (15) & BRAVE (20) & NALTO (5) & SAEKI (27) \\
\hline 5 & KAIHO (7) & AWARD (18) & BLITS (17) & KARIN (22) & ASAMI (5) & ALISA (22) \\
\hline 6 & AVION (2) & ARLON (5) & BRASS (8) & BECKY (7) & BAGLE (9) & TANTA (13) \\
\hline 7 & ALLIE (2) & APOLO (15) & BACON (3) & EVIAN (13) & TOMO (8) & AJE (32) \\
\hline 8 & AZURE (4) & RW34L & BIBLO (2) & ASAMI (13) & HAMAR (14) & MAYAH (7) \\
\hline 9 & RW34L & - & BEAST (3) & TOMO (8) & MAYAH (7) & BB450 (2) \\
\hline 10 & - & - & BONDO (13) & HAMAR (14) & BB450 (2) & BB451 (3) \\
\hline 11 & - & - & RWY22 & MAYAH (7) & BB451 (3) & BB452 (2) \\
\hline 12 & - & - & - & BB450 (2) & BB452 (2) & BEIGE (3) \\
\hline 13 & - & - & - & BB451 (3) & BEIGE (3) & RW24R \\
\hline 14 & - & - & - & BB452 (2) & RW24R & - \\
\hline 15 & - & - & - & BEIGE (3) & - & - \\
\hline 16 & - & - & - & RW24R & - & - \\
\hline
\end{tabular}

\section{Profile descent}

\subsection{Deviations in the PD vertical profiles}

A total of seven trials were carried out to simulate PD using the B777-200 and B787-800 full flight simulators, as shown in Table 1. Figure 3 shows the PD profiles for altitude, path angle, calibrated airspeed (CAS), thrust, and speed brake.

Figure $3 \mathrm{a}, \mathrm{b}$ shows the PD vertical profiles of the seven trials obtained through altitude and path angle records. These figures demonstrate the individual PD profiles and their diversity of vertical profiles. The vertical profiles of PD-KH1 and PD-RA in Fig. 3a shows a difference of 30.1 NM-in the along-track distance at FL350 - between the point where PD-KH1 crossed FL350 during descent and the point where PD-RA started the descent at FL350. A difference of 16.3 NM was observed at the TOD position (where the aircraft started the descent), between the B777-200 trial PD-KH1 and the B787-200 trial PD-KH2, because of the difference in aircraft performance. Table 8 summarizes the mean and deviations in PD path angle profiles of the above three trials: PD-KH1, PDRA, and PD-KH2. As shown in Table 8, for the B777-200 an average of $3.186^{\circ}$ under winter wind was selected in the PD-KH1 trial, but in the B787800 case a shallower angle was selected, with an average of $2.549^{\circ}$ (also under winter wind and for the same flight route of the PD-KH2 trial). The B777-200 performed at an average of $2.435^{\circ}$ under summer wind in the PD-RA trial. These results indicate that the PD vertical profiles could vary according to different aircraft types and wind conditions. The pilots had manual control of the speed brakes to avoid overspeed, and of the flap angles and gear for approach/landing during the PD trials. The other controls were automatically operated by the FMS.

Figures 4 and 5 compare the maximum variation in the altitude and path angle profiles among the seven PD trials, at every $10 \mathrm{NM}$ of distance-to-go from the runway threshold. The major factors determining these variations are the difference in aircraft performance (because of the different aircraft types) and the weather effects (including the wind speed and directions of both the actual wind and the wind estimated in the FMS following each air route, and the estimation errors between them). Figure 4 shows a comparison between six different B777-200 trials. Figure 5 shows a comparison between the B777-200 PD-KH1 trial and the B787-800 PD-KH2 trial. Given that two of the B777-200 PD trials (PD-KR and PD-RA) were terminated before landing, Fig. 4 compares the values only until 20 NM before the runway. A maximum deviation of 8690 $\mathrm{ft}$ was obtained between the altitude profiles of the two trials-as denoted in Fig. 4-at a point $110 \mathrm{NM}$ before the runway threshold. Path angle deviations between $0.9^{\circ}$ and $5.1^{\circ}$ were obtained on the descent phase. In Fig. 5, a maximum deviation range of $6130 \mathrm{ft}$ was obtained at a position $100 \mathrm{NM}$ before the runway threshold. The path angles deviated from $1.0^{\circ}$ to $4.6^{\circ}$ on the descent phase. Although the maximum variability in the altitude profiles decreased as the aircraft approached the runway threshold, 
Table 4 Wind inputs (speed, direction, altitude, and the corresponding waypoint name) into the FMS

\begin{tabular}{|c|c|c|c|}
\hline 1st layer & 2nd layer & 3rd layer & 4th layer \\
\hline \multicolumn{4}{|c|}{$\begin{array}{l}\text { Trials on the arrival route/ } \underline{R U N W A Y} \text { following SMOLT via KAIHO } \\
\text { to ILS Y } \underline{R W Y 34 L}\end{array}$} \\
\hline $74 \mathrm{kn}$ & $75 \mathrm{kn}$ & $35 \mathrm{kn}$ & 14 kn \\
\hline $287^{\circ}$ & $272^{\circ}$ & $272^{\circ}$ & $263^{\circ}$ \\
\hline $38,000 \mathrm{ft}$ & $25,000 \mathrm{ft}$ & $10,000 \mathrm{ft}$ & $6000 \mathrm{ft}$ \\
\hline SMOLT & SHOES & PQE & KAIHO \\
\hline \multicolumn{4}{|c|}{$\begin{array}{l}\text { Trials on the arrival route/RUNWAY following SMOLT via ARLON } \\
\text { to ILS Z } \underline{R W Y 34 L}\end{array}$} \\
\hline $74 \mathrm{kn}$ & $76 \mathrm{kn}$ & $34 \mathrm{kn}$ & $10 \mathrm{kn}$ \\
\hline $287^{\circ}$ & $285^{\circ}$ & $268^{\circ}$ & $286^{\circ}$ \\
\hline $38,000 \mathrm{ft}$ & $25,000 \mathrm{ft}$ & $10,000 \mathrm{ft}$ & $5000 \mathrm{ft}$ \\
\hline SMOLT & CHEVY & ADDUM & ARLON \\
\hline \multicolumn{4}{|c|}{$\begin{array}{l}\text { Trials on the arrival route/ } \underline{R U N W A Y} \text { following SMOLT via BACON } \\
\text { to LDA W } \underline{R W Y 22}\end{array}$} \\
\hline $39 \mathrm{kn}$ & $28 \mathrm{kn}$ & $13 \mathrm{kn}$ & $5 \mathrm{kn}$ \\
\hline $255^{\circ}$ & $269^{\circ}$ & $267^{\circ}$ & $216^{\circ}$ \\
\hline $35,000 \mathrm{ft}$ & $10,000 \mathrm{ft}$ & $5000 \mathrm{ft}$ & $0 \mathrm{ft}$ \\
\hline SMOLT & ADDUM & BONDO & RWY22 \\
\hline \multicolumn{4}{|c|}{$\begin{array}{l}\text { Trials on the arrival route/RUNWAY following MADOG via KARIN } \\
\text { to ILS Y } \underline{R W Y 24 R}\end{array}$} \\
\hline $6 \mathrm{kn}$ & $26 \mathrm{kn}$ & 37 kn & 14 kn \\
\hline $325^{\circ}$ & $341^{\circ}$ & $207^{\circ}$ & $192^{\circ}$ \\
\hline $39,000 \mathrm{ft}$ & $29,000 \mathrm{ft}$ & $5000 \mathrm{ft}$ & $0 \mathrm{ft}$ \\
\hline MADOG & STORK & MAYAH & RWY24R \\
\hline \multicolumn{4}{|c|}{$\begin{array}{l}\text { Trials on the arrival route/RUNWAY following SALTY via RANDY } \\
\text { to ILS Y } \underline{R W Y 24 R}\end{array}$} \\
\hline 14 kn & $30 \mathrm{kn}$ & 37 kn & $14 \mathrm{kn}$ \\
\hline $340^{\circ}$ & $322^{\circ}$ & $207^{\circ}$ & $192^{\circ}$ \\
\hline $39,000 \mathrm{ft}$ & $28,000 \mathrm{ft}$ & $5000 \mathrm{ft}$ & $0 \mathrm{ft}$ \\
\hline FUE & SALTY & MAYAH & RWY24R \\
\hline \multicolumn{4}{|c|}{$\begin{array}{l}\text { Trials on the arrival route/RUNWAY following CHILY via SAEKI to } \\
\text { ILS Y RWY24R }\end{array}$} \\
\hline $20 \mathrm{kn}$ & $43 \mathrm{kn}$ & $37 \mathrm{kn}$ & $14 \mathrm{kn}$ \\
\hline $198^{\circ}$ & $326^{\circ}$ & $207^{\circ}$ & $192^{\circ}$ \\
\hline $36,000 \mathrm{ft}$ & $28,000 \mathrm{ft}$ & $5000 \mathrm{ft}$ & $0 \mathrm{ft}$ \\
\hline SQUID & SAEKI & MAYAH & RWY24R \\
\hline
\end{tabular}

the observed values of altitude variability cause difficulties to ATCos when handling the overall air traffic. There are several intersections on the air routes in the en-route airspace. As per one of the standards, the vertical separation between aircraft has to be larger than $1000 \mathrm{ft}$ above FL290 on the cruise. However, the altitude variability observed in PD is larger than the requirement (more than $3000 \mathrm{ft}$ on the descent phase and more than $50 \mathrm{NM}$ away from the runway threshold, as shown in Figs. 4, 5). This is not operationally acceptable for ATCos that need to handle high-density air traffic.
Table 5 Wind inputs (speed, direction, and altitude) into the flight simulator computer system

\begin{tabular}{llll}
\hline 1st layer & 2nd layer & 3rd layer & 4th layer \\
\hline $\begin{array}{l}\text { Trials on the arrival routel } \\
\text { to ILS } Y \underline{\text { RWY } 34 L} \text { L }\end{array}$ & & & \\
& $72 \mathrm{kn}$ & $21 \mathrm{kn}$ & $7 \mathrm{kn}$ \\
$93 \mathrm{kn}$ & $275^{\circ}$ & $291^{\circ}$ & $258^{\circ}$ \\
$267^{\circ}$ & $25,000 \mathrm{ft}$ & $10,000 \mathrm{ft}$ & $0 \mathrm{ft}$
\end{tabular}

Trials on the arrival route/RUNWAY following SMOLT via ARLON to ILS Z $\underline{R W Y 34 L}$

$\begin{array}{llll}93 \mathrm{kn} & 72 \mathrm{kn} & 20 \mathrm{kn} & 3 \mathrm{kn} \\ 267^{\circ} & 275^{\circ} & 248^{\circ} & 271^{\circ} \\ 38,000 \mathrm{ft} & 25,000 \mathrm{ft} & 10,000 \mathrm{ft} & 5000 \mathrm{ft}\end{array}$

Trials on the arrival route/RUNWAY following SMOLT via BACON to $L D A W \underline{R W Y 22}$

$\begin{array}{llll}39 \mathrm{kn} & 28 \mathrm{kn} & 7 \mathrm{kn} & 3 \mathrm{kn} \\ 252^{\circ} & 265^{\circ} & 252^{\circ} & 210^{\circ} \\ 35,000 \mathrm{ft} & 10,000 \mathrm{ft} & 5000 \mathrm{ft} & 0 \mathrm{ft}\end{array}$

Trials on the arrival route/RUNWAY following MADOG via KARIN to ILS Y $\underline{R W Y 24 R}$

$\begin{array}{llll}10 \mathrm{kn} & 30 \mathrm{kn} & 40 \mathrm{kn} & 13 \mathrm{kn} \\ 7^{\circ} & 344^{\circ} & 219^{\circ} & 197^{\circ} \\ 39,000 \mathrm{ft} & 29,000 \mathrm{ft} & 10,000 \mathrm{ft} & 0 \mathrm{ft}\end{array}$

Trials on the arrival route/RUNWAY following SALTY via RANDY to ILS Y $\underline{R W Y 24 R}$

$\begin{array}{llll}14 \mathrm{kn} & 30 \mathrm{kn} & 40 \mathrm{kn} & 13 \mathrm{kn} \\ 340^{\circ} & 332^{\circ} & 219^{\circ} & 197^{\circ} \\ 35,000 \mathrm{ft} & 28,000 \mathrm{ft} & 10,000 \mathrm{ft} & 0 \mathrm{ft}\end{array}$

Trials on the arrival route/RUNWAY following CHILY via SAEKI to ILS Y $\underline{R W Y 24 R}$

\begin{tabular}{llll}
$16 \mathrm{kn}$ & $45 \mathrm{kn}$ & $40 \mathrm{kn}$ & $13 \mathrm{kn}$ \\
$164^{\circ}$ & $331^{\circ}$ & $219^{\circ}$ & $197^{\circ}$ \\
$36,000 \mathrm{ft}$ & $28,000 \mathrm{ft}$ & $10,000 \mathrm{ft}$ & $0 \mathrm{ft}$ \\
\hline
\end{tabular}

\subsection{Control usage during PD}

The CAS, thrust, and speed brake profiles are shown in Fig. 3c-e. The aircraft maintained the ECON speed established in the FMS, based on the given CI values. Figure 3d, e show the thrust and speed brake controls during PD. Theoretically, PD is carried out with minimum thrust. If a speed reduction is required, pilots control the speed brakes manually, given that this control is not automated. The autopilot and autothrottle control pitch angle and air speed to conserve the total energy of the aircraft. Given that VNAV/ PATH mode was selected during the trials, the priority of the autopilot was to follow the assigned vertical path, not speed control. As shown in Fig. 3e, the pilots manually controlled the speed brakes during the PD trials to maintain the aircraft below the maximum operational speed. One of the reasons for the speed increase was the existence of wind estimation errors in the FMS. 
Table 6 FPA settings

\begin{tabular}{|c|c|c|c|}
\hline \multirow[t]{2}{*}{ Trial name } & & \multicolumn{2}{|l|}{ FPA settings (deg) } \\
\hline & & TOD to ADDUM & ADDUM to AZURE \\
\hline \multicolumn{4}{|c|}{ B777-200 trials following "SMOLT via ARLON to ILS Z $\underline{R W Y 34 L "}$} \\
\hline \multicolumn{2}{|c|}{ FPA-AR-35-30 } & 3.5 & 3.0 \\
\hline \multicolumn{2}{|l|}{ FPA-AR-30-25 } & 3.0 & 2.5 \\
\hline \multicolumn{2}{|l|}{ FPA-AR-30-22 } & 3.0 & 2.2 \\
\hline \multicolumn{2}{|l|}{ FPA-AR-25-22 } & 2.5 & 2.2 \\
\hline \multicolumn{2}{|l|}{ FPAS-AR-25-22 } & 2.5 & 2.2 \\
\hline \multirow{2}{*}{\multicolumn{2}{|c|}{ Trial name }} & \multicolumn{2}{|l|}{ FPA settings (deg) } \\
\hline & & TOD to ADDUM & ADDUM to BONDO \\
\hline \multicolumn{4}{|c|}{ B777-200 trials following "SMOLT via BACON to LDA W $\underline{\mathrm{RWY22}}$ " } \\
\hline \multicolumn{2}{|c|}{ FPA-BA-30-27 } & 3.0 & 2.7 \\
\hline \multicolumn{2}{|l|}{ FPA-BA-27-25 } & 2.7 & 2.5 \\
\hline \multicolumn{2}{|l|}{ FPA-BA-25-22 } & 2.5 & 2.2 \\
\hline \multicolumn{2}{|l|}{ FPAS-BA-25-22 } & 2.5 & 2.2 \\
\hline Trial name & FPA & & \\
\hline & TOD & & \\
\hline B777-200 trials fol & $N$ to $I$ & & \\
\hline FPA-KR-30 & 3.0 & & \\
\hline FPA-KR-25 & 2.5 & & \\
\hline FPA-KR-22 & 2.2 & & \\
\hline FPAS-KR-22 & 2.2 & & \\
\hline Trial name & & FPA settings (deg) & \\
\hline & & TOD to PQE & PQE to AZURE \\
\hline B787-800 trials fol & to $I L$ & & \\
\hline FPA-KH2-27-22 & & 2.7 & 2.2 \\
\hline FPA-KH2-22-20 & & 2.2 & 2.0 \\
\hline FPAS-KH2-22-20 & & 2.2 & 2.0 \\
\hline
\end{tabular}

Table 7 Pilot inputs to perform FPA descents following one of the selected arrival routes "SMOLT via ARLON to ILS Z RWY34L"

\begin{tabular}{|c|c|c|c|c|}
\hline \multirow{2}{*}{$\begin{array}{l}\text { Waypoint name (distance to } \\
\text { the next waypoint; } \mathrm{NM} \text { ) }\end{array}$} & \multicolumn{4}{|l|}{ FL/altitude (feet) } \\
\hline & FPA-AR-35-30 & FPA-AR-30-25 & FPA-AR-30-22 & FPA-AR-25-22 \\
\hline SMOLT (92; to TOMMY) & FL380 & FL380 & FL380 & FL380 \\
\hline \multicolumn{5}{|l|}{ TOM01 (30; to TOMMY) } \\
\hline TOM02 (20; to TOMMY) & & & & FL375 \\
\hline TOM03 (5; to TOMMY) & & & FL378 & \\
\hline TOMMY (56) & FL380 & FL372 & - & - \\
\hline \multicolumn{5}{|l|}{ CHV01 (45; to CHEVY) } \\
\hline CHV02 (40; to CHEVY) & FL369 & & & \\
\hline CHEVY (20) & - & - & - & - \\
\hline ADDUM (7) & 14,500 & 12,900 & 12,000 & 12,000 \\
\hline AWARD (18) & - & - & - & - \\
\hline ARLON (5) & - & - & - & - \\
\hline APOLO (FAF) (15) & $(5000)$ & $(5000)$ & $(5000)$ & $(5000)$ \\
\hline RW34L & - & - & - & - \\
\hline
\end{tabular}




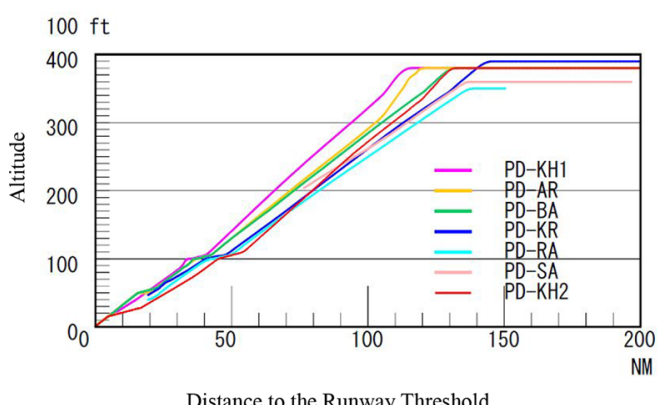

(a)

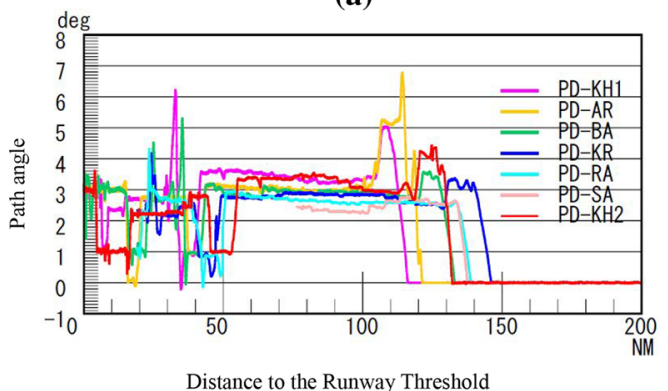

(b)

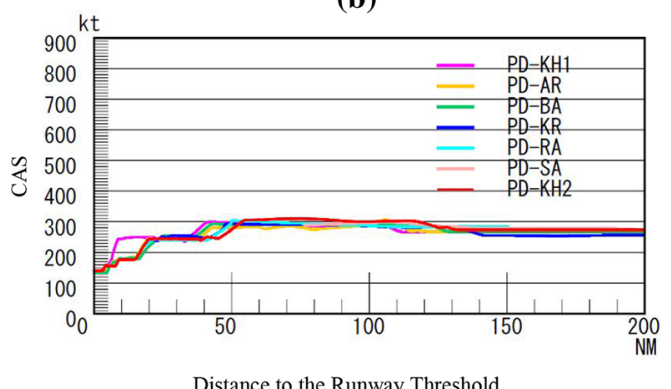

(c)

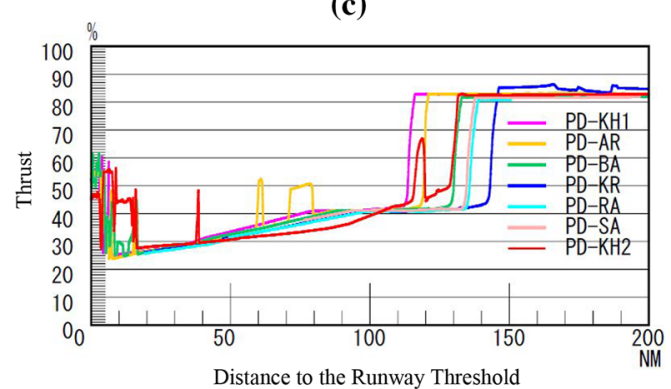

(d)

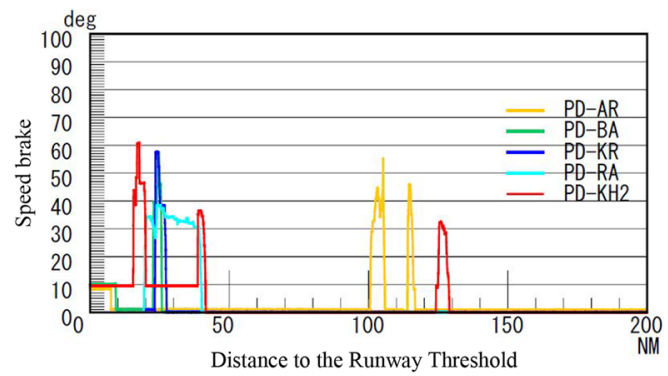

(e)

Fig. 3 Considered PD profiles (seven trials). a Altitude. b Path angle. c CAS. d Thrust. e Speed brake

\subsection{PD impacts in air traffic}

As indicated by the experimental results of the PD trials, the aircraft descends to the assigned runway following the individual aircraft trajectory generated by the FMS. The aircraft trajectories in the FMS are currently not shared with the ATCos on the ground; therefore, these unpredictable (from the point of view of the ATCo) individual aircraft trajectories during PD lead ATCos to increase the separation intervals between the aircraft and other traffic, to maintain safety. Therefore, current PD is applicable only in low-density air traffic.

Although the departure and arrival/approach air routes are clearly separated in terminal areas, the air route structures in en-route areas are complex, including aircraft arriving/ departing to and from different directions, and overflights at different levels of altitude; this is especially so around the congested metroplex areas in Japan. Because of this air traffic complexity, air traffic controllers have posed requests to improve the estimation of the CDO aircraft altitude-especially at the points of aircraft hand-off to their corresponding airspace - to maintain air traffic safety.

To improve the predictability of aircraft trajectories and still be able to apply energy-saving approaches in congested airspace covering both en-route and terminal areas, this study suggests applying FPA descent, in which arrivals continuously descend to the assigned runway following fixed vertical path angles. Compared with PD, FPA descent reduces the uncertainties in predicting the altitude profile; therefore, it facilitates ATCo operation and contributes to support the use of energy-saving arrivals in high-density operation environments.

\section{Fixed flight-path angle descent}

\subsection{Fixed flight-path angle descent concept}

Figure 6 explains the concept of FPA descent $[11,16]$. Several merging points are given on a vertical path with descent angle $\gamma$. Four merging points are set at FL200, FL250, FL300, and FL350: arrivals cruising above FL360 merge to the FPA descent path at FL350, arrivals cruising above FL310 but below FL360 merge at FL300, arrivals cruising above FL260 but below FL310 merge at FL250 and, finally, arrivals cruising above FL210 but below FL260 merge at FL200. In this approach, FPA descent does not specify the position/altitude of the TOD of arrival aircraft. Because of the different possible TOD altitudes, FPA descent provides altitude options to the arrival aircraft concerning the point where they begin the continuous descent. The FPA values should be selected to minimize fuel consumption within the assigned arrival time constraints. 
Table 8 Mean and standard deviation values of PD path angle profiles

\begin{tabular}{lllll}
\hline Trial & $\begin{array}{l}\text { PD-KH1 (TOD-20 } \\
\text { NM prior to runway } \\
34 \mathrm{~L})\end{array}$ & $\begin{array}{l}\text { PD-KH1 } \\
\text { (TOD-runway } \\
34 \mathrm{~L})\end{array}$ & $\begin{array}{l}\text { PD-RA (TOD-20 NM } \\
\text { prior to runway 24L) }\end{array}$ & $\begin{array}{l}\text { PD-KH2 } \\
\text { (TOD-runway } \\
\text { 34L) }\end{array}$ \\
\hline Mean value (deg) & 3.186 & 3.039 & 2.435 & 2.549 \\
Standard deviation (deg) & 0.9047 & 0.8644 & 0.6175 & 0.9419 \\
\hline
\end{tabular}

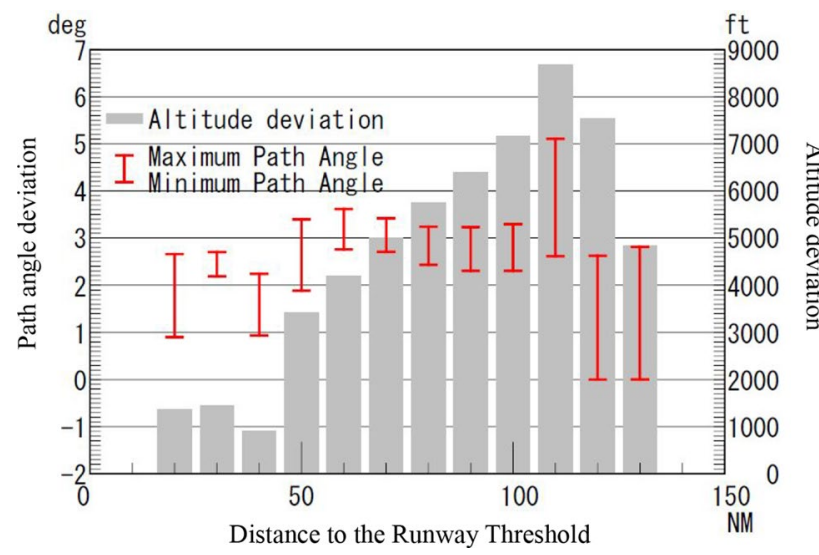

Fig. 4 Deviations in the altitude and path angle profiles for the six B777-200 PD trials

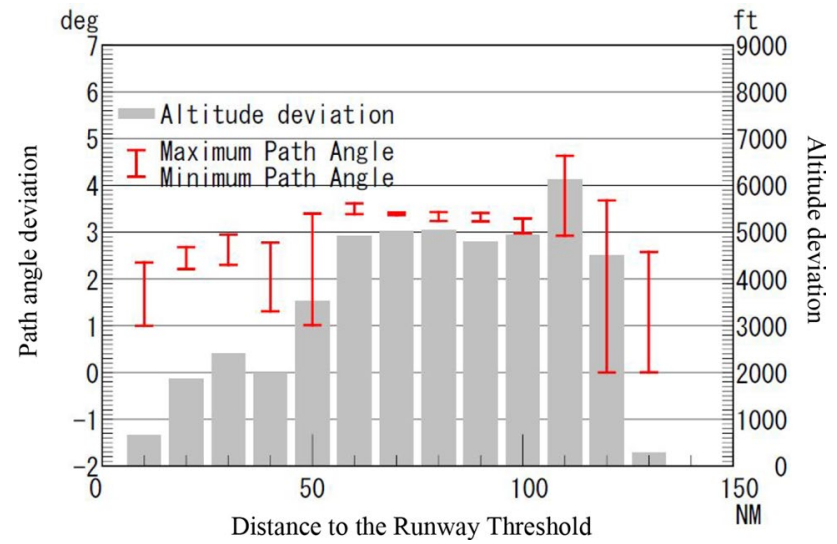

Fig. 5 Deviations in the altitude and path angle profiles for the B777200 and B787-800 PD trials

The expected benefits of FPA descent stem directly from the improved predictability of the resulting vertical profiles. As discussed in Sect. 3, both the altitude records and the position of TOD presented deviations in the PD vertical profiles. In contrast, applying FPA descent can reduce the deviations, if such a descent is operationally feasible by the aircraft. In particular, by improving the ground-based aircraft trajectory predictability, FPA descent is expected to bring benefits in ATM fuel-efficiency, because it leads to a lower rate of cancellation of energy-saving arrivals (which also leads to the reduction of step-descent and arrival

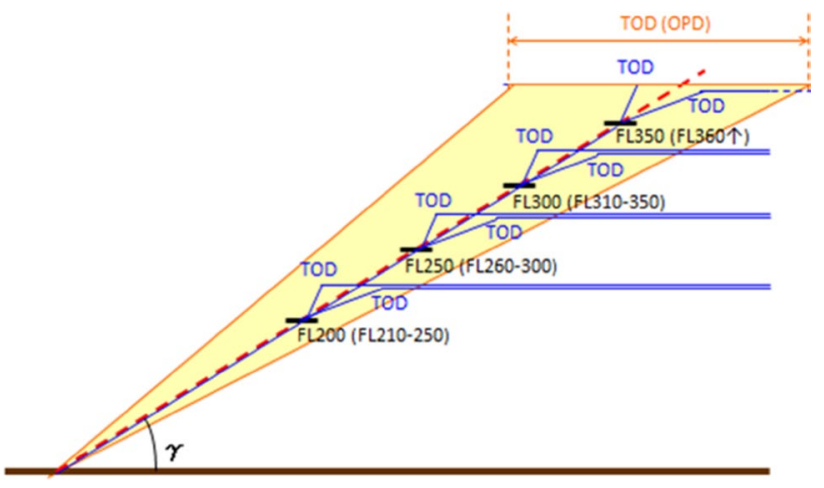

Fig. 6 FPA descent concept, as compared with the vertical deviations in PD profiles [10]

vectoring). Additionally, ETA prediction by ground operators will become more accurate, thereby improving the performance of the ground automation tools that support arrival time scheduling for ATCos. Finally, if the arrival trajectory is more predictable, it becomes easier to avoid interferences with departure and fly-over traffic. Therefore, FPA descent is expected to help achieve more effective departure management and metering operations, something that is also directly related to airport management efficiency. One of the main requirements when implementing novel operation methods is that of maximizing the ATM operational efficiency. The proposed FPA descent addresses this requirement directly: it is a potential implementation that achieves environmentfriendly operations while satisfying the required ATM efficiency.

\subsection{Control and tracking performance on the assigned FPA vertical path}

To analyze the operational feasibility of FPA descent, 12 trials were conducted targeting the Tokyo and Kansai International Airports, as summarized in Table 1. The FPA settings for these trials were selected between $2.0^{\circ}$ and $3.5^{\circ}$, as shown in Table 6.

Figures 7, 8, 9 and 10 compare the altitude, path angle, CAS, thrust, and speed brake profiles of the FPA descent and PD trials: the B777-200 flight profiles for the "SMOLT via ARLON to ILS RWY34L" route are shown in Fig. 7, the B777-200 flight profiles for "SMOLT via BACON to 


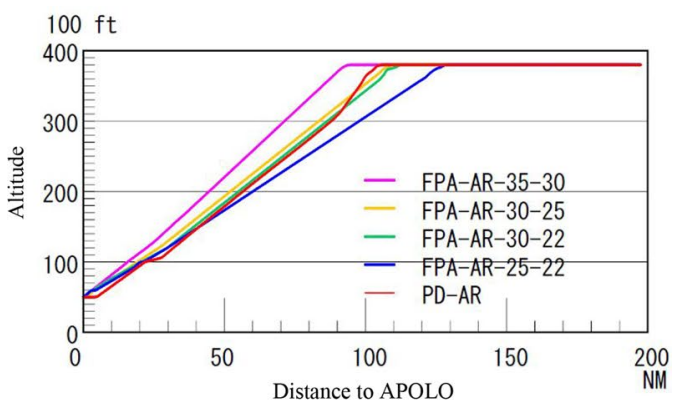

(a)

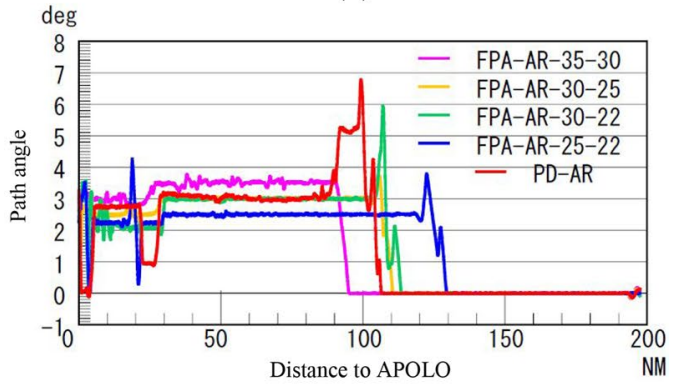

(b)

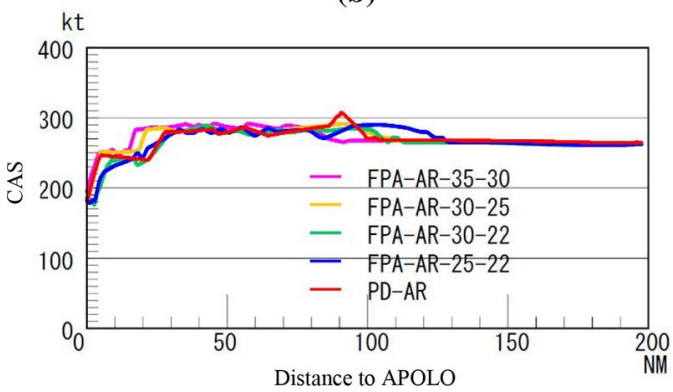

(c)

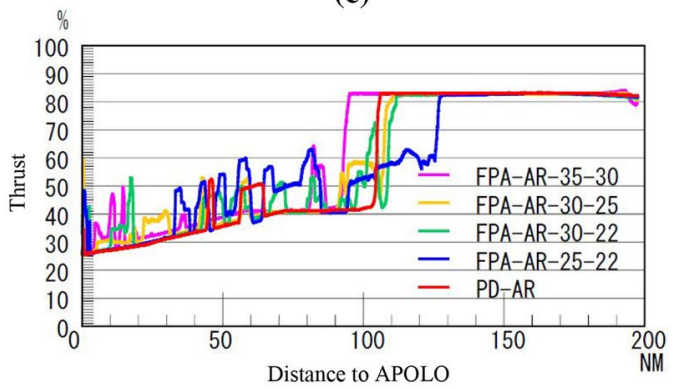

(d)

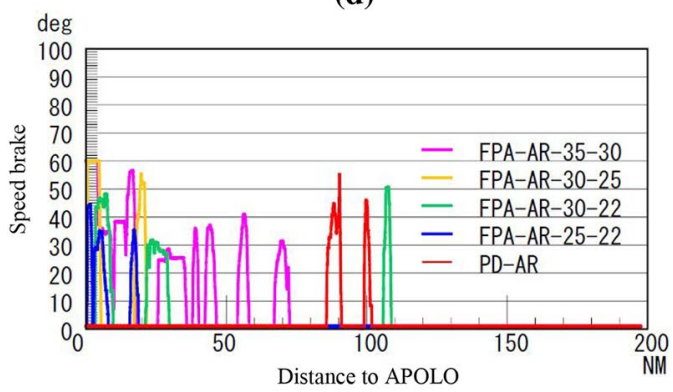

(e)

Fig. 7 FPA descent and PD profiles for the B777-200 on the "SMOLT via ARLON to ILS RWY34L" route. a Altitude. b Path angle. c CAS. d Thrust. e Speed brake

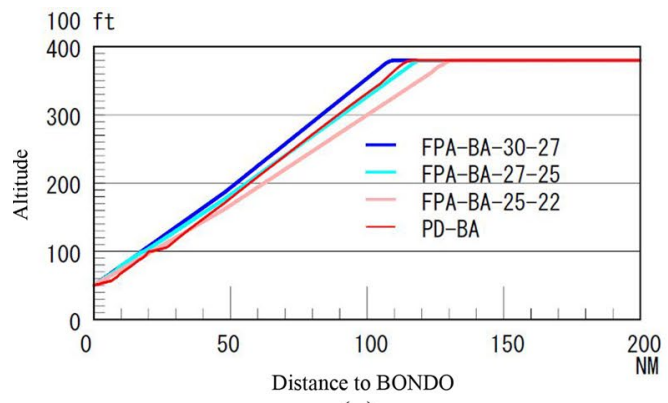

(a)

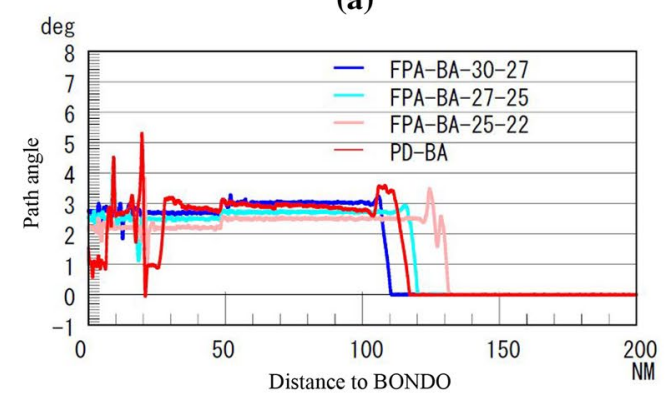

(b)

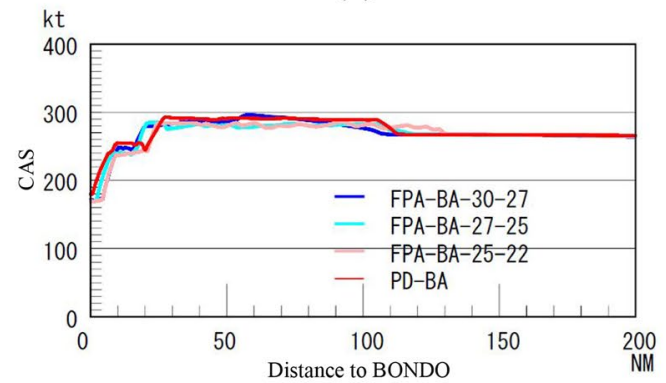

(c)

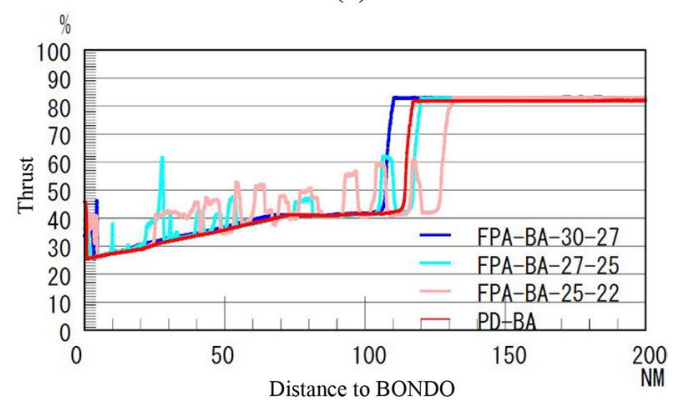

(d)

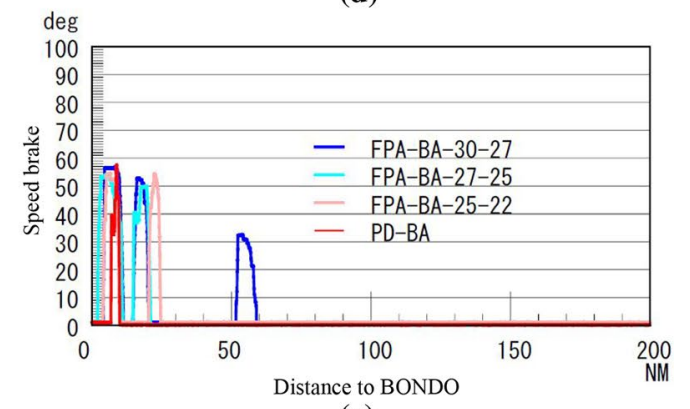

(e)

Fig. 8 FPA descent and PD profiles for the B777-200 on the "SMOLT via BACON to LDA W RWY22" route. a Altitude. b Path angle. c CAS. d Thrust. e Speed brake 


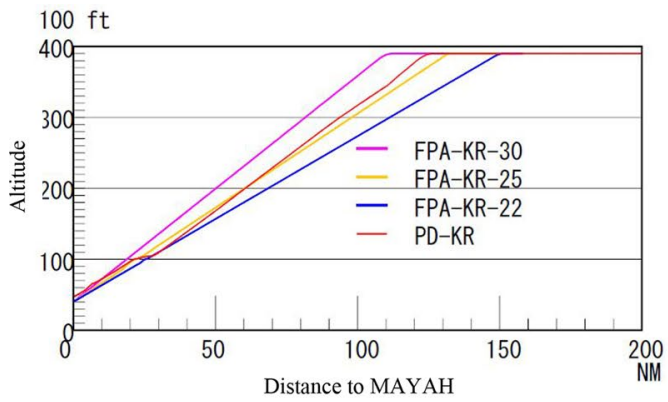

(a)

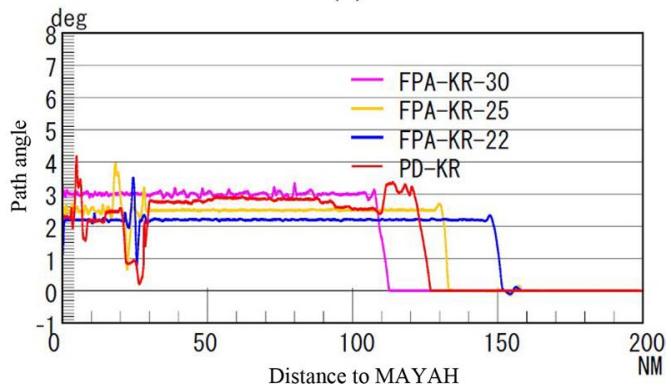

(b)

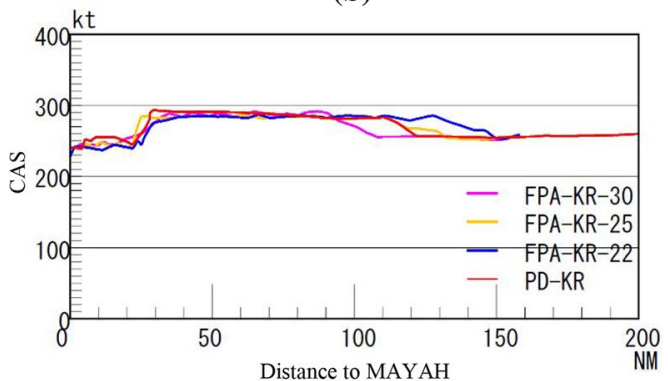

(c)

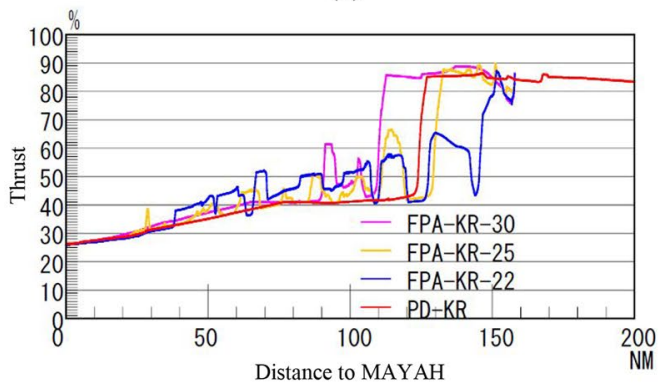

(d)

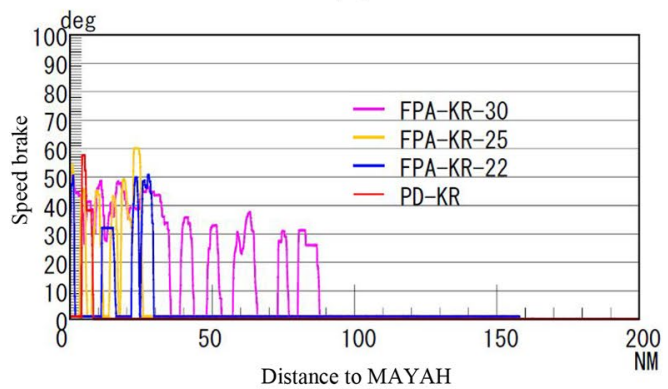

(e)

Fig. 9 FPA descent and PD profiles for the B777-200 on the "MADOG via KARIN to ILS Y RWY24R" route. a Altitude. b Path angle. c CAS. d Thrust. e Speed brake

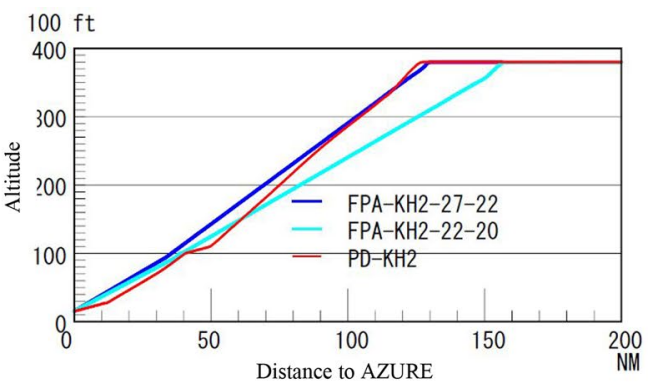

(a)

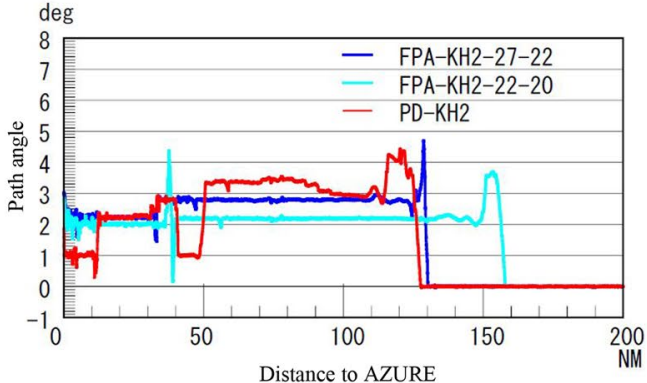

(b)

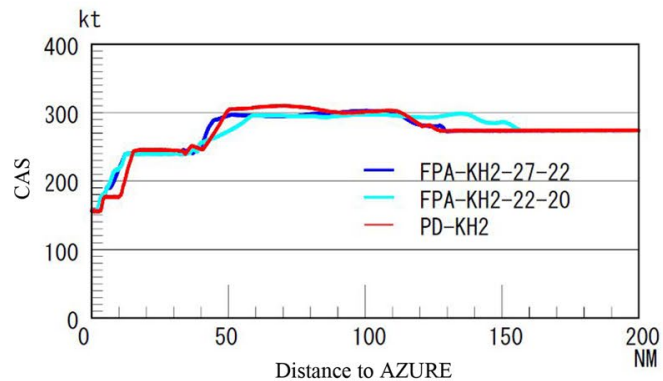

(c)

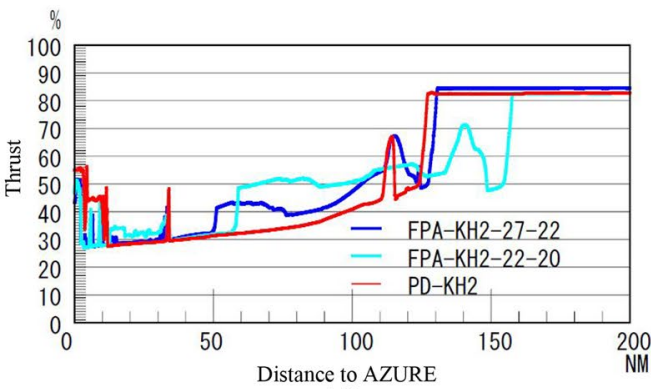

(d)

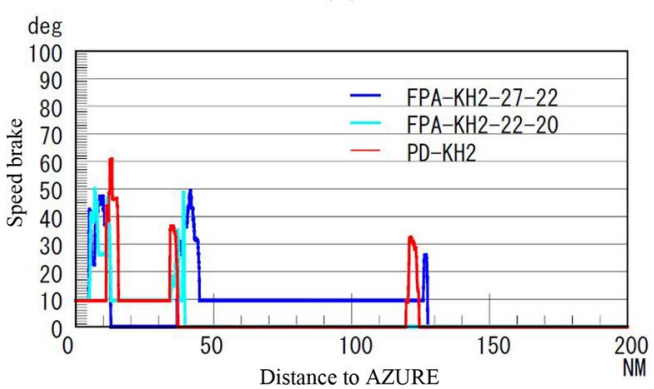

(e)

Fig. 10 FPA descent and PD profiles for the B787-800 on the "SMOLT via KAIHO to ILS Y RWY34L" route. a Altitude. b Path angle. c CAS. d Thrust. e Speed brake 
LDA W RWY22" are shown in Fig. 8, the B777-200 flight profiles for "MADOG via KARIN to ILS Y RWY24R" are shown in Fig. 9 and, finally, the B787-800 flight profiles for "SMOLT via KAIHO to ILS Y RWY34L" are shown in Fig. 10. These altitude and path angle profiles indicate that both the B777-200 and B787-800 could achieve FPA descent following the assigned FPA vertical paths-the ones that continuously connected the altitude constraints input by the pilots via the CDU. Table 9 shows the mean and standard deviation of the path angles during FPA descent, and the altitude deviations at assigned waypoints on the FPA vertical paths. The deviation between altitude profiles and the assigned FPA descent in Table 9 is operationally applicable. The experimental results shown in Figs. 7, 8, 9 and 10 and Table 9 demonstrate that FPA descent achieves operationally acceptable tracking performance on the assigned vertical path, and that it is operationally feasible by controlling the thrust and speed brakes under the assumptions adopted in the experiments.

\subsection{Fuel consumption and flight time}

The fuel consumption and flight times of the FPA descent and PD trials are compared in Figs. 11 and 12. For the comparison, experimental data were extracted from the following arrival routes: SMOLT to APOLO on the "SMOLT via ARLON to ILS Z RWY34L" route, SMOLT to BONDO on the "SMOLT via BACON to LDA W RWY22" route, SUC to MAYAH on the "MADOG via KARIN to ILS Y RWY24R" route, and SMOLT to AZURE on the "SMOLT via KAIHO to ILS Y RWY34L" route. Figure 11 show the fuel consumption (in the cruise and descent phases) and flight time for the PD and FPA descents trials. Figure 12 shows the increase in fuel consumption and flight time of the FPA descent trials relative to PD.

As shown in Fig. 11, FPA descent with shallower path angles could shorten the cruise distances and thus reduce fuel consumption during the cruise phase. However, FPA descent with shallower path angles increases fuel consumption during the descent. The fuel consumption per unit time varies with the joint effect of winds and CI values. The effects of fuel consumption reduction in the cruise phase were especially noticeable in flights with strong head winter winds (the FPA-AR and FPA-KH2 trials), as shown in Fig. 12, where the FPA-AR trials (B777-200) and FPA-KH2 trials (B787-800) are seen to achieve fuel efficient FPA descents by reducing the cruise distance. Some of these FPA descent trials achieved even better fuel efficiency than the PD trials. As mentioned above, this results from the combined effects of the wind and the CI values. Generally, the airlines determine the CI values by considering the economic trade-offs between flight time and fuel consumption, based on their particular strategies. The airborne-equipped
FMS calculates its PD profile for those CI settings considering the estimated wind datasets, which differ from the actual wind effects. Even though additional experimental data are required concerning the FMS inputs needed to conduct FPA descents with higher efficiency than PD, the experimental results presented here are indicative of general trends concerning the fuel efficiency of the FPA descent compared with that of PD. In the FPA-KR trials, the smallest FPA selection could minimize fuel consumption. When compared with the PD trial, the FPA-BA trials could not achieve remarkable fuel reductions with the selected FPA settings. One of the assumed reasons is that the given FPA values are not optimal under the given conditions. In future experiments, additional variable FPA settings will be used to verify this assumption. With the decrease in FPA values, the flight time is increased. Even though the selection of FPA values remains an open topic for future work, these results indicate that the most fuel-efficient FPA settings depend on aircraft dynamics, FMS settings, and wind effects on the arrival routes.

\subsection{Operational feasibility of FPA descent}

The above-discussed experimental results demonstrate the feasibility of FPA descent, with acceptable tracking performance on the assigned FPA vertical path, using the FMS equipped currently equipping B777-200 and B787-800 aircraft. Fuel-efficient FPA descent was achieved especially under strong head wind conditions, because the shallower FPA values shortened the cruise distance. Given that the flight time could be controlled by FPA selection, this creates the potential to adjust air traffic arrival time, if this approach is used instead of conventional operations. A further discussion of this topic will be held and summarized in Sect. 6 .

One of the important factors to discuss is the pilots' workload implied by the need to input the FPA settings via CDU. Prior to the FPA descent, the pilots were requested to input altitude constraints, as shown in the examples on Table 7 . The pilot's inputs to the CDU were done as follows, in the case of the FPA-AR-25-22 trial shown in Table 7. First, the pilot created a new waypoint "TOM02" $30 \mathrm{NM}$ before the TOMMY waypoint. Second, the pilot input two altitude constraints: FL375 at TOM02, and 12,000 ft at ADDUM. These CDU operations were naturally performed by the pilots without any notable workload increase, because in current operations the pilots already operate the CDU to set the descent path before effectively starting the descent. The requested FPA descent was, therefore, perceived as a mere increase of three additional inputs - the ones mentioned above-during the current CDU operation.

The pilots and airline operational experts' comments on the flight-simulator-based FPA descent experiments were as follows: 


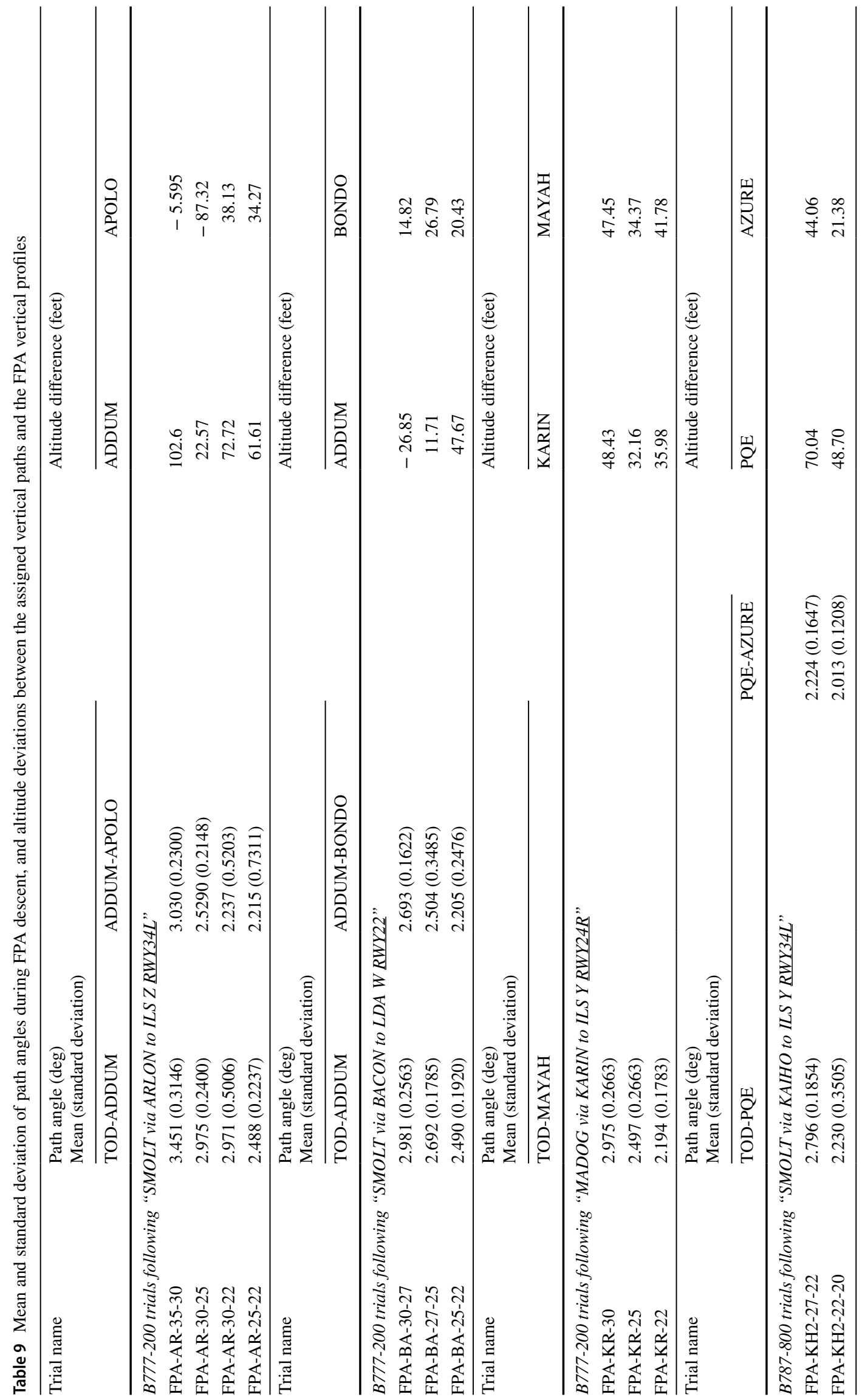




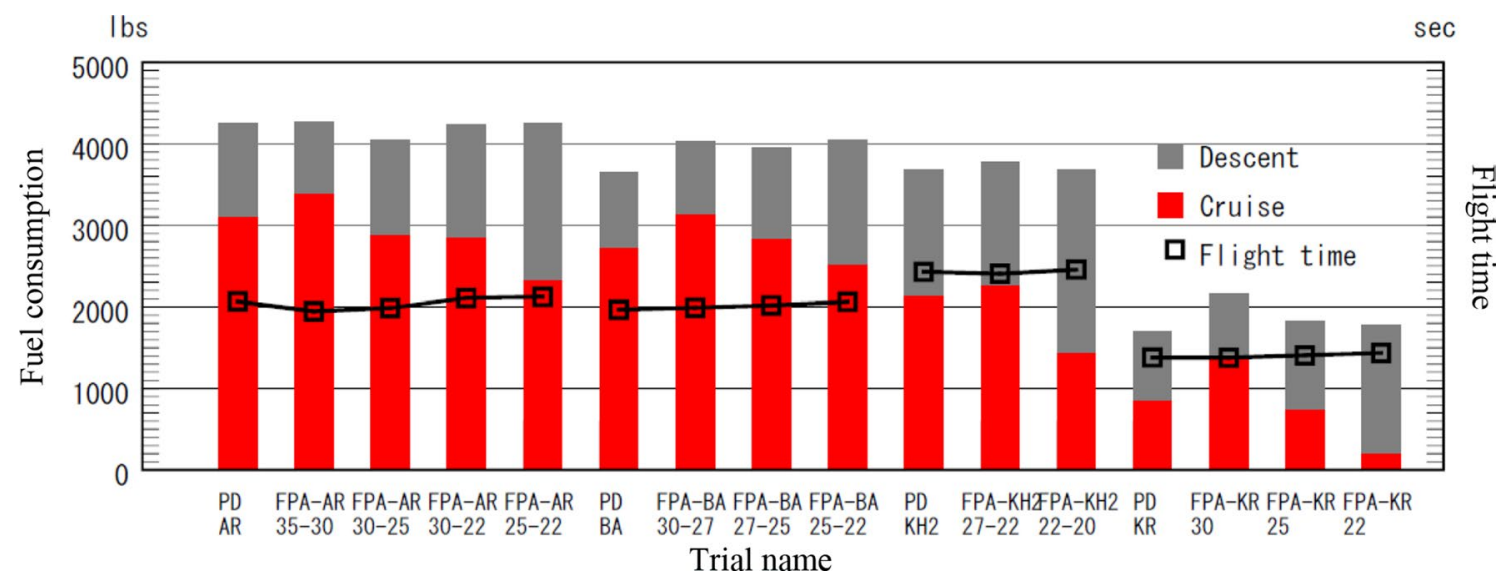

Fig. 11 Fuel consumption and flight times for the PD and FPA descents (the $y$ axes have the same scale)

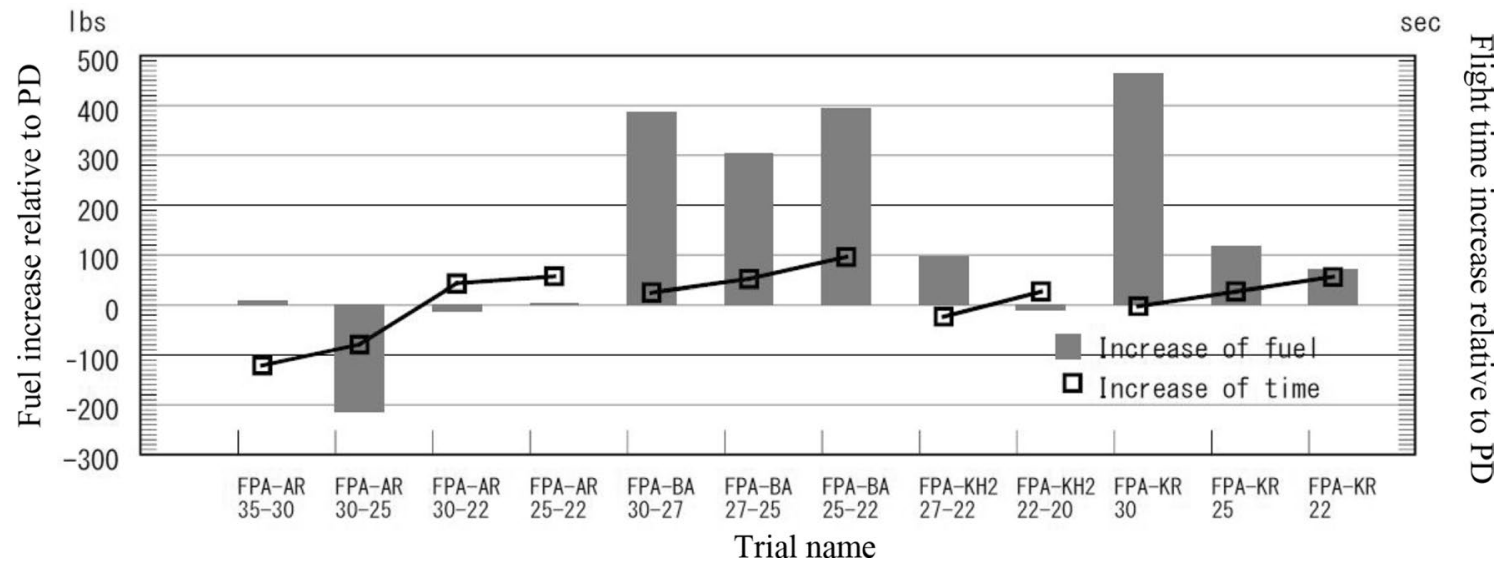

Fig. 12 Increase in fuel consumption and flight time of the FPA descents relative to PD (the $y$ axes have the same scale)

- The pilots were required to create waypoints and altitude constraints at corresponding waypoints to define the FPA vertical path in FMS via CDU. This procedure was operationally feasible, and the pilots' workload was acceptable.

- Even though the feasible FPA values depended on wind effects, air routes, and aircraft types, higher FPA values implied a more frequent need for pilot control of the speed brakes, to follow the FPA vertical path within the speed constraints. Frequent control of speed brakes by the pilots is better avoided in real operations.

- As felt by the pilots, the selection of FPA values around $2.5^{\circ}$ could achieve operationally stable flights for B777-200 aircraft. If the assigned FPA values were less than $2.5^{\circ}$, the pilots felt that the FPA descent was operationally stable, given that the thrust and speed brakes were under pilot control. When the assigned FPA values were steeper than $2.5^{\circ}$, the pilots felt that the aircraft speed reductions (e.g., less than $250 \mathrm{kn}$ at
$10,000 \mathrm{ft}$ ) were slow and not controlled by the thrust and speed brakes as they expected.

- Given that shallower flight-path angles are preferred for the B787-800 aircraft than for the B777-200, the FPA values for the B787-800 were required to be smaller than those for B777-200 under the same operational conditions.

- Considering passenger comfort, FPA values steeper than $3.5^{\circ}$ were deemed not desirable, so that pressure changes can be avoided.

- Shallower FPA values increased flight time. In current air traffic operations, ATCos issue radar vectors to delay arrival times because of traffic situations. For fuel efficiency, it was considered preferable to delay arrival time by FPA descent than by issuing radar vectors.

The above comments indicate that FPA descent is operationally feasible by selecting FPA values that take into account the perspectives of passengers' comfort, 
pilots' controllability, arrival delay adjustment, and fuel efficiency.

\section{Speed control in PD and FPA descent}

\subsection{Operational procedures for speed control}

Speed control is one of the potential options to control arrival time and time spacing between the surrounding traffic while conducting CDO. A total of six trials were carried out to evaluate the effect of speed control during PD and FPA descents: two trials involved speed control during PD, and four trials involved speed control during FPA descent, as shown in Table 1 . Speed instructions were verbally given to the pilot from pseudo ATCo in the cockpit, a total of four times, as shown in Table 10. The speed instructions were selected to mimic the ones of speed control in current arrival operations. The pilot tried to control the aircraft speed to follow the received speed instructions while continuously descending to the runway; during the FPA descent trials, the pilots controlled the aircraft to follow both the speed instructions and the defined FPA vertical path.

There are two methods for pilots to control aircraft speed via the Vertical NAVigation (VNAV) mode. One is to control a speed tab on the mode control panel and adjust aircraft speed while the VNAV/SPEED mode is on. Given that the autopilot prioritizes airspeed control in this method, the aircraft has the potential to deviate from the assigned vertical path; the pilot then manually controls the throttle lever and speed brakes to keep the aircraft on the assigned vertical path. This method has the potential to increase the pilots' workload. The other method is to input the speed command into the DESCENT page in the FMC while VNAV/ PATH mode is on. In this method, the FMC recalculates the required thrust to satisfy the altitude constraints while changing speed. The benefit of the second method is the lower pilot workload when compared to the first. However, if the autothrottle is not capable of achieving the required performance, the pilot is required to control the speed brakes manually, because that is not automated. This paper uses the second method, to analyze the operational feasibility of speed control during PD and FPA descent.

\subsection{Control and tracking performance on the assigned speed and vertical path}

Figure 13 shows the altitude, path angle, CAS, thrust, and speed brake profiles of the two trials in which speed control was carried out during PD (see Table 1). For comparison, profiles of the PD trials are also shown in this figure. Comparing with PD operation, it may be seen that the pilots actively controlled the speed brakes to comply with the assigned speed. All speed commands could be respected through the pilots' manual control of the speed brakes during PD.

Figure 14 shows the altitude, path angle, CAS, thrust, and speed brake profiles of the four trials in which speed control was carried out during FPA descent (see Table 1). For comparison, the corresponding FPA descents-in which the same FPA values were established-are also shown in this figure. Table 11 summarizes the altitude deviation, and the mean and standard deviation of the path angle profiles in the four trials. The pilots controlled aircraft speed as instructed, while keeping the aircraft altitude on the assigned FPA vertical path. They commented that shallower path angles made speed control more stable. Although the selection of FPA values depends on the wind conditions and aircraft characteristics, FPA values lower than $2.5^{\circ}$ were considered desirable, to obtain an accurate tracking performance and ensure operational feasibility from the point of view of the pilot. Frequent speed change instructions should be avoided, to minimize the pilots' workload, as stated in Sect. 4.4.

\subsection{Fuel consumption and flight time}

Eight trials with FPA values shallower than $2.5^{\circ}$ were selected for comparison of fuel consumption and flight time, as illustrated in Figs. 15, 16 and 17. Figure 15 shows the fuel consumption and flight times for a total of 14 trials of PD, speed control with PD, FPA descent, and speed control with FPA descent. Figure 16 shows the increment in fuel consumption and flight time of the speed control with PD, FPA

Table 10 Assigned speed commands

\begin{tabular}{|c|c|c|c|c|}
\hline Trial name & 1st speed command & 2nd speed command & 3rd speed command & 4th speed command \\
\hline $\begin{array}{l}\text { PDS-KR } \\
\text { FPAS-KR-22 }\end{array}$ & $265 \mathrm{kn}$ at BRAVE & $245 \mathrm{kn}$ at KARIN & $235 \mathrm{kn}$ at EVIAN & $210 \mathrm{kn}$ at TOMO \\
\hline $\begin{array}{l}\text { PDS-KH2 } \\
\text { FPAS-KH2-22-20 }\end{array}$ & $280 \mathrm{kn}$ at $30 \mathrm{NM}$ prior to SHOES & $270 \mathrm{kn}$ at SHOES & $240 \mathrm{kn}$ at $25 \mathrm{NM}$ prior to $\mathrm{PQE}$ & $210 \mathrm{kn}$ at $\mathrm{PQE}$ \\
\hline FPAS-AR-25-22 & $265 \mathrm{kn}$ at $17 \mathrm{NM}$ prior to $\mathrm{CHEVY}$ & $245 \mathrm{kn}$ at $\mathrm{CHEVY}$ & $235 \mathrm{kn}$ at $\mathrm{ADDUM}$ & $210 \mathrm{kn}$ at AWARD \\
\hline FPAS-BA-25-22 & $265 \mathrm{kn}$ at $30 \mathrm{NM}$ prior to $\mathrm{CHEVY}$ & $245 \mathrm{kn}$ at $\mathrm{CHEVY}$ & $235 \mathrm{kn}$ at $\mathrm{ADDUM}$ & $210 \mathrm{kn}$ at BLITZ \\
\hline
\end{tabular}




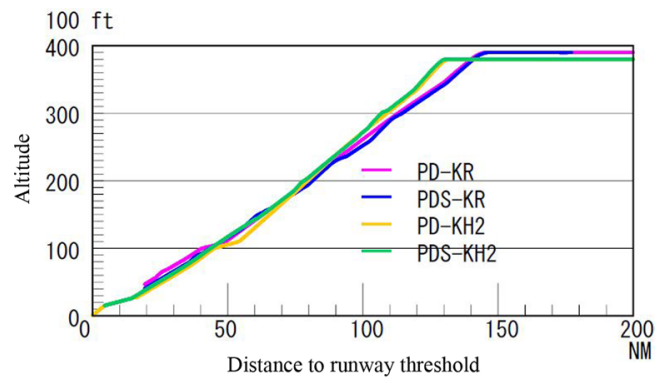

(a)

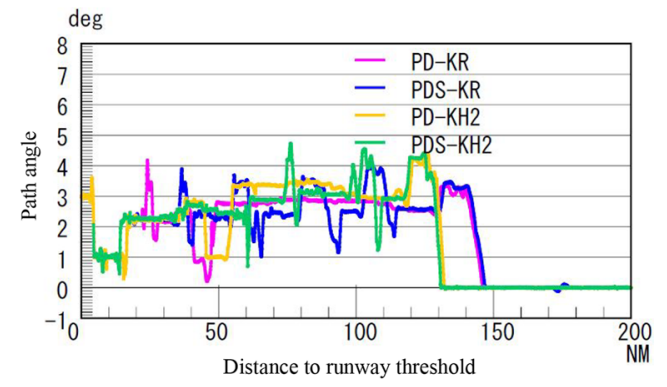

(b)

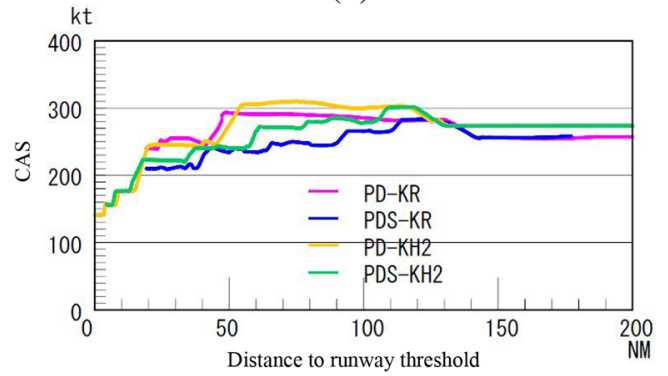

(c)

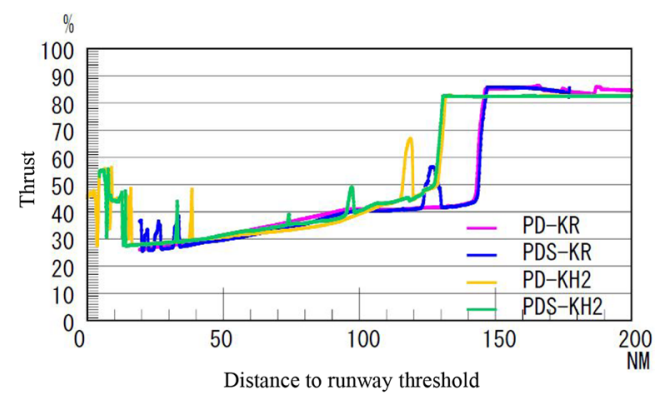

(d)

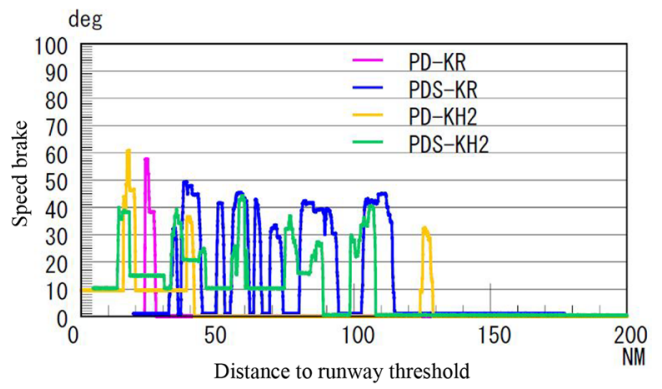

(e)

Fig. 13 Speed control profiles during PD. a Altitude. b Path angle. c CAS. d Thrust. e Speed brake

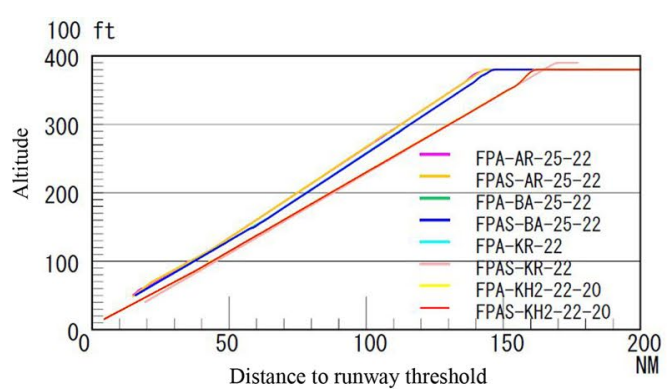

(a)

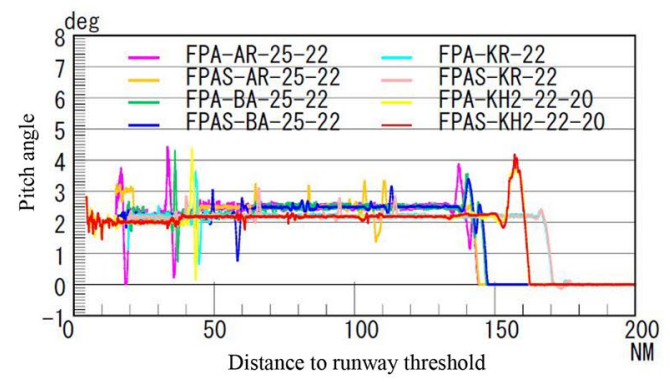

(b)

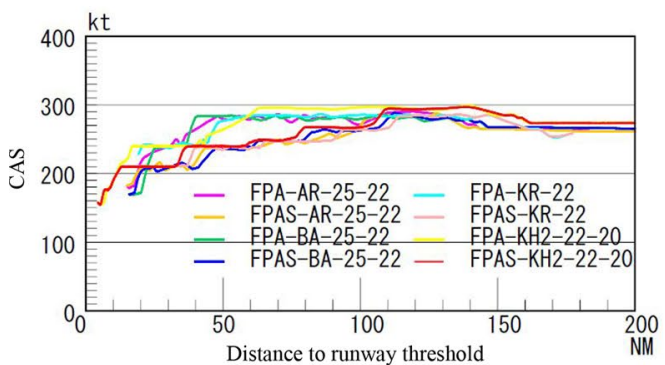

(c)

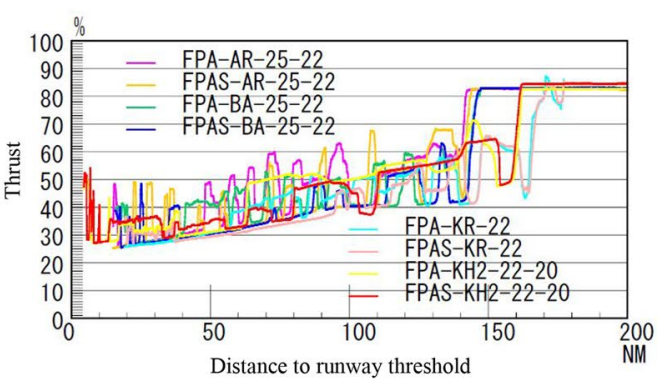

(d)

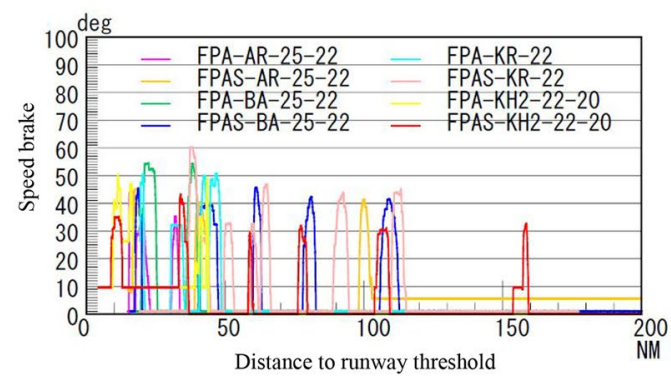

(e)

Fig. 14 Speed control profiles during FPA descent. a Altitude. b Path angle. $\mathbf{c}$ CAS. d Thrust. e Speed brake 
Table 11 Altitude deviation, and mean and standard deviation values of path angle profiles for six trials with speed control during FPA descent

\begin{tabular}{lllcc}
\hline Trial & FPAS-AR-25-22 & FPAS-BA-25-22 & FPAS-KR-22 & FPAS-KH2-22-20 \\
\hline Altitude difference (feet) & 66.02 (30 NM prior to & -7.860 (30 NM prior to & -54.75 (30 NM prior to & 39.19 (30 NM prior to \\
& APOLO) & BONDO) & MAYAH) & AZURE) \\
& -155.0 (APOLO) & 21.24 (BONDO) & 22.57 (MAYAH) & 32.621 (AZURE) \\
Path angle & 2.489 & 2.490693 & 2.194 & 2.227 \\
Mean value (deg) & $(0.2003)$ (TOD-ADDUM) & $(0.1826)($ TOD-ADDUM) & $(0.1198)$ (TOD-MAYAH) & $(0.2685)($ TOD-PQE) \\
Standard deviation (deg) & 2.294 & 2.195 & & 2.013 \\
& $(0.4115)($ ADDUM- & $(0.2036)($ ADDUM- & & $(0.1160)($ PQE-AZURE) \\
& APOLO) & BONDO) & & \\
\hline
\end{tabular}

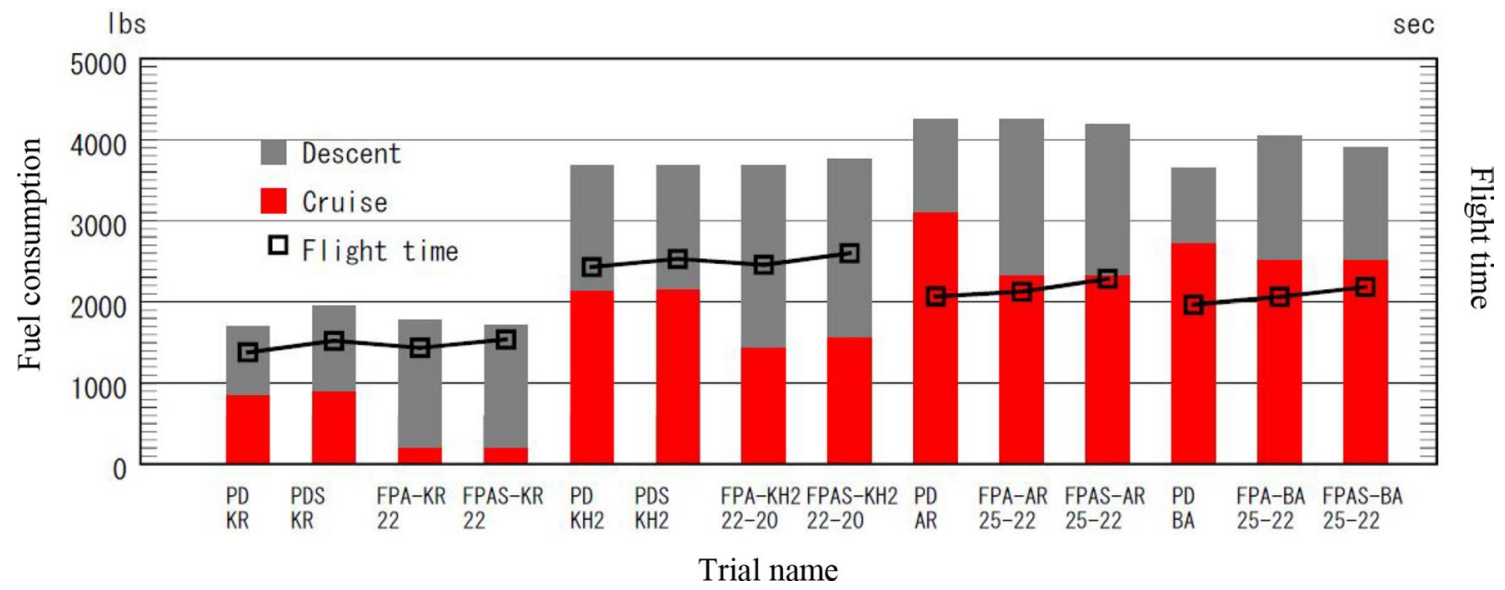

Fig. 15 Comparison of fuel consumption and flight times (the $y$ axes have the same scale)

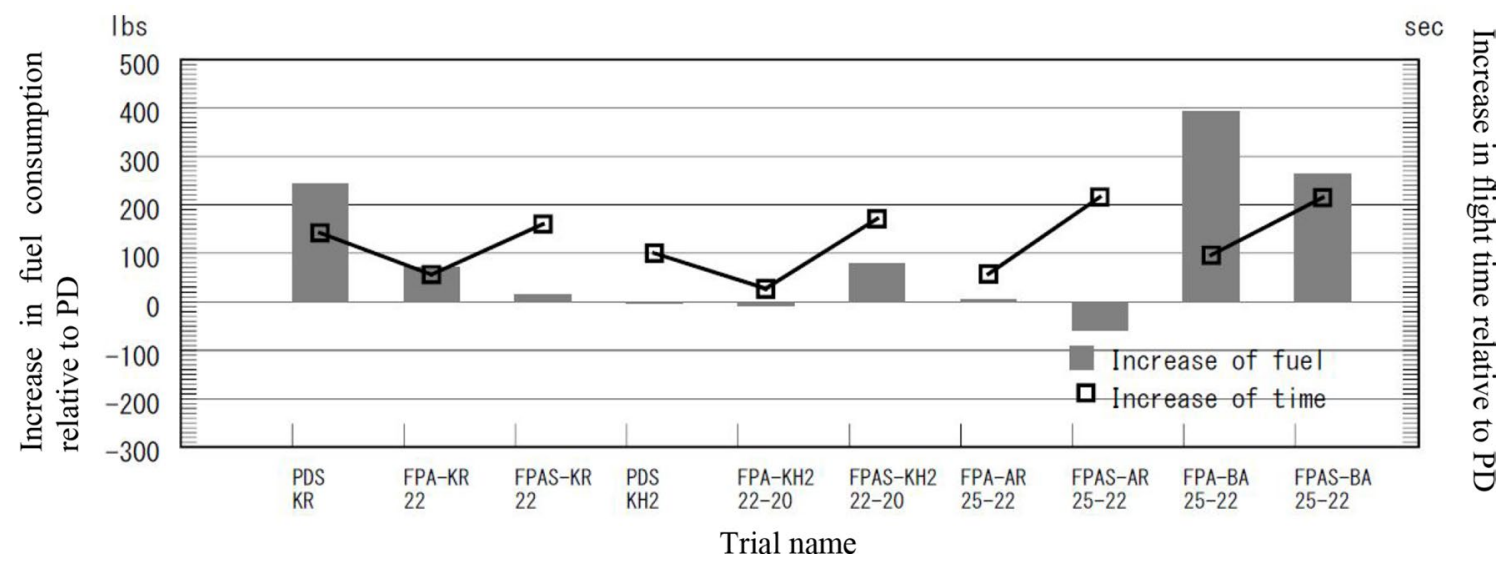

Fig. 16 Increase in fuel consumption and flight times relative to the PD trials (the $y$ axes have the same scale)

descent, and speed control with FPA descent trials relative to the corresponding PD trials. Figure 17 shows the increase in the fuel consumption rate of the speed control with PD, FPA descent, and speed control with FPA descent trials relative to the corresponding PD trials.

Comparing the four B777-200 trials on the arrival route "MADOG via KARIN to ILS Y RWY24R", it can be seen that the speed control with FPA descent could achieve the most fuel-efficient descent, while absorbing the arrival time delay. In the four B787-800 trials following the arrival route "SMOLT via KAIHO to ILS Y RWY34L", the FPASKH2-22-20 trial (speed control with FPA descent) could achieve a fuel-efficient descent, achieving the second minimum fuel consumption value. Although it was not the most 


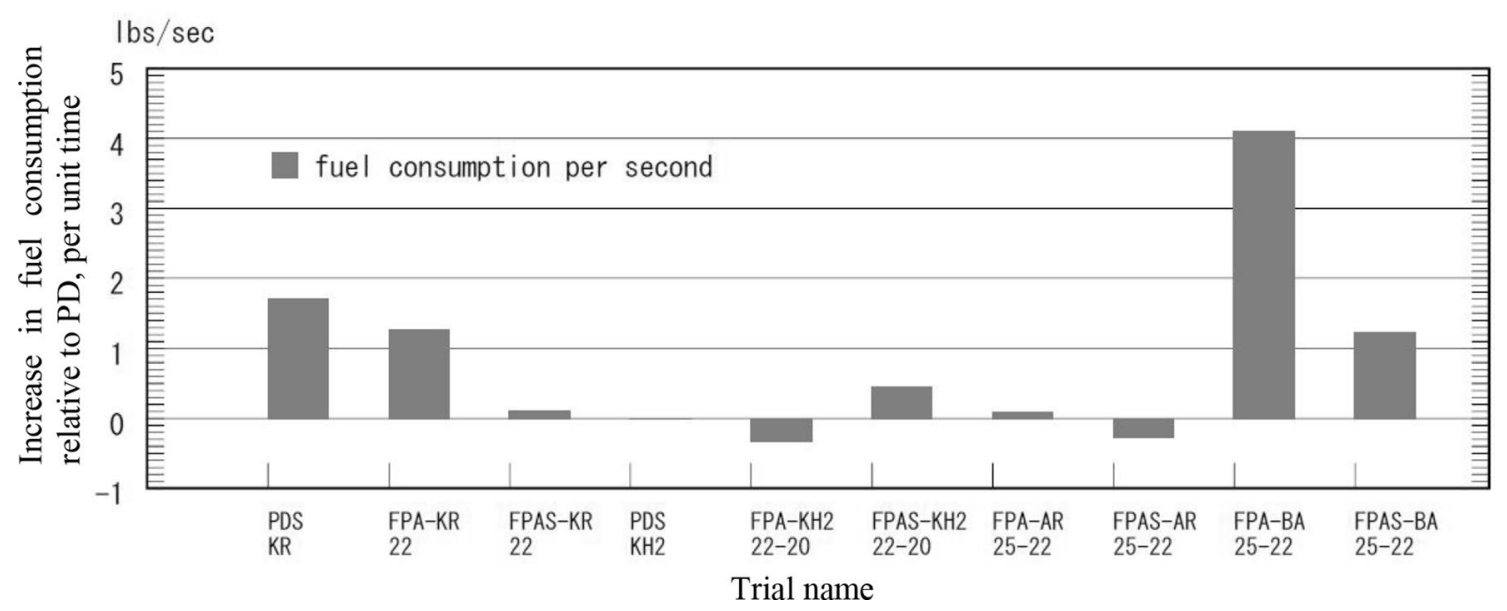

Fig. 17 Fuel consumption rate increase (the $y$ axes have the same scale)

fuel-efficient descent among the four trials, it could be one of the efficient options to handle arrival delay. In the other trials, the speed control during FPA descent FPASAR-25-22 and FPAS-BA-25-22 trials did reduce fuel consumption compared with FPA descent. The FPAS-AR-25-22 trial could even reduce fuel consumption to less than that of the PD trial, while extending the flight time. Although the same FPA settings were assigned to the FPA trials on the arrival routes "SMOLT via ARLON to ILS Z RWY34L" and "SMOLT via BACON to LDA W RWY22", fuel consumption was increased during the FPA descent on "SMOLT via BACON to LDA W RWY22" under summer winds. Assigning fuel-optimal FPA settings according to the wind conditions will achieve even better fuel efficiency in speed control approaches.

\section{Comparison with conventional arrival operations}

\subsection{Profiles of conventional arrival operations using the Kansai International Airport}

To comparatively evaluate the fuel efficiency of the proposed FPA descent, a series of experiments were carried out to simulate conventional arrival operations. Five trials considering arrivals at the Kansai International Airport were selected, as shown in Table 2 . These trials simulate conventional operations aimed at managing both the arrival time and the spacing among the surrounding traffic, as explained in Table 12. Figure 18 shows the horizontal position, altitude, path angle, CAS, thrust, and speed brake profiles for the five trials.

\subsection{Comparison of fuel consumption and flight time}

This section discusses the fuel efficiency of FPA descent compared with that of conventional arrival operations.

Table 12 Trials on the conventional arrival operations to Kansai International Airport

\begin{tabular}{ll}
\hline Trial name & Remarks \\
\hline DES-KR & ATCo operation to descend the aircraft before the optimal TOD position to ensure spacing from surrounding traffic \\
RTA-KR & $\begin{array}{r}\text { RTA operation in which the ATCo asks the pilot to use the RTA function in the FMC to delay the arrival time at } \\
\text { the KARIN waypoint by } 2 \text { min, when the aircraft cruises at } ~ 40 \text { NM before MADOG. The KARIN waypoint } \\
\text { is located at the boundary between the en-route and terminal airspaces. The arriving aircraft is transferred to } \\
\text { terminal control at the KARIN waypoint }\end{array}$ \\
ATCo uses radar vectoring between MADOG and STORK \\
PV1-KR & PD attempt cancelled at $10,000 \mathrm{ft}$ to maintain altitude for spacing from other arrival traffic \\
PDC-KR & PD trials in which the STAR route is updated to extend the arrival routes. Therefore, in this trial, ATCo uses radar \\
vDA-KR & vectoring in the terminal area to ensure spacing from departure traffic
\end{tabular}




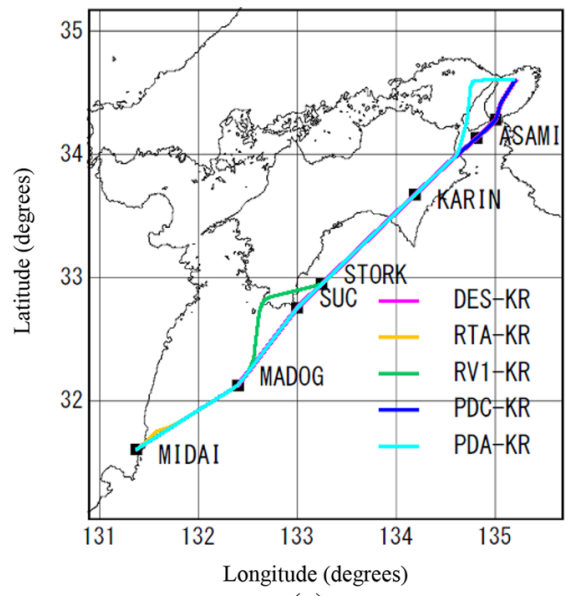

(a)

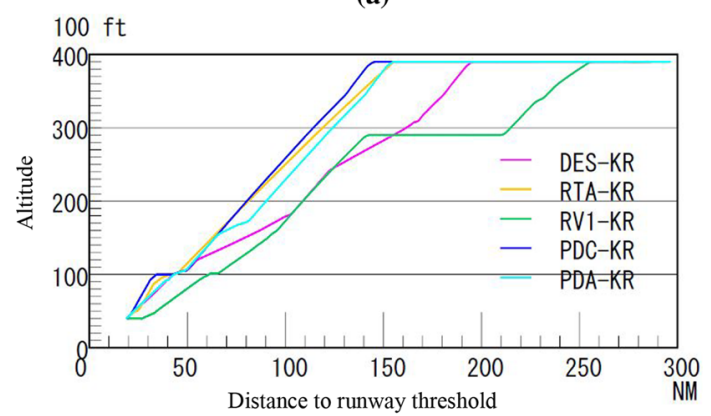

(b)

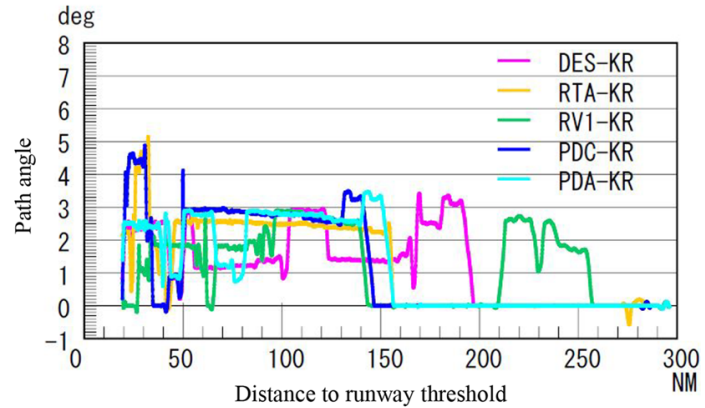

(c)

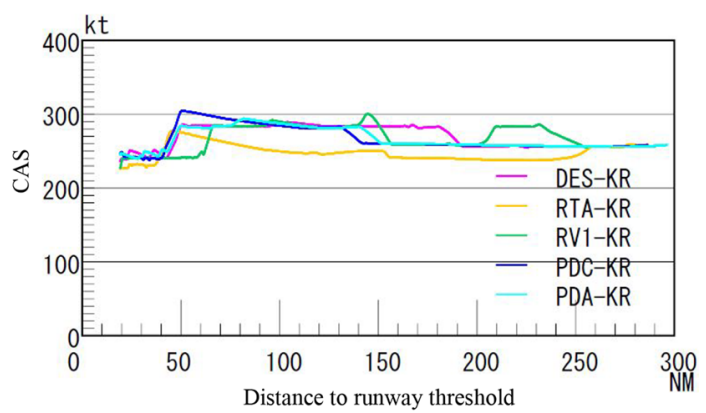

(d)

Fig. 18 Profiles of conventional arrival operations (five trials). a Horizontal flight path. b Altitude. $\mathbf{c}$ Path angle. d CAS. e Thrust. f Speed brake

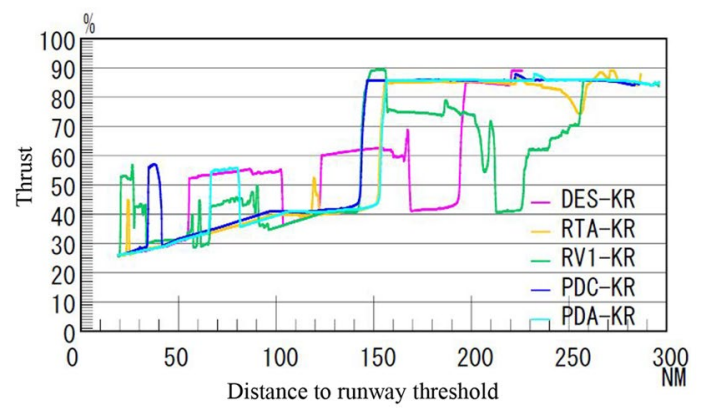

(e)

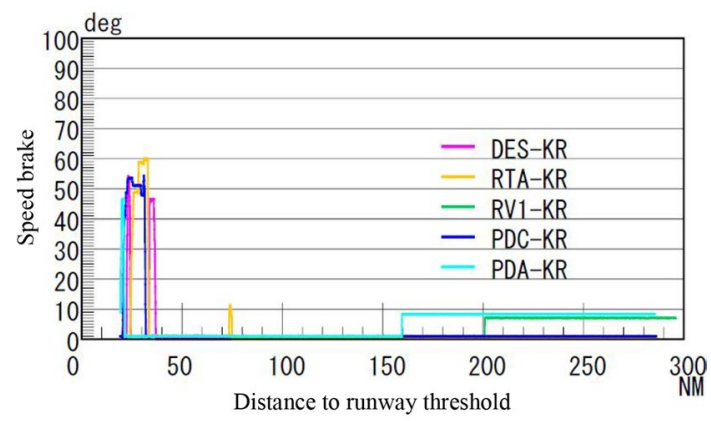

(f)

Fig. 18 (continued)

Figure 19 shows the fuel consumption and flight time of 11 trials (PD, PD with speed control, conventional operations, FPA descent, and FPA descent with speed control) arriving at the Kansai International Airport along the "MADOGKARIN-ILS Y RWY 24R" arrival route. Figure 20 shows the increment in fuel consumption and flight time of the ten trials when compared with the PD trial. The fuel consumption increase was also normalized by the flight time increment from the PD trial, and the results are shown in Fig. 21. These results indicate that the most fuel-efficient operation was RTA operation, the second one being the combination of speed control with FPA descent. As discussed in Sect. 4, FPA descent with shallower FPA settings could reduce the total amount of fuel consumption by shortening the cruise phase. The FPA-KR-30 trial took the steepest FPA and performed an earlier arrival than the PD trial, but increased fuel consumption by speeding up through the extension of the cruising flight. Speed control with FPA descent in the FPAS-KR-22 trial could achieve a more fuel-efficient descent than speed control during PD in the PDS-KR trial. As shown in Fig. 21, the most fuel-consuming operation was the cancelled PD in the PDC-KR trial. Although applying ATCo's radar vectoring in the RV1-KR trial could absorb the longest arrival delay, the experimental results indicate that combining speed control in RTA operation and FPA descent has the potential to result in more efficient arrival operations. However, the RTA function in the FMS of the B777-200 flight simulator was not capable of controlling the 


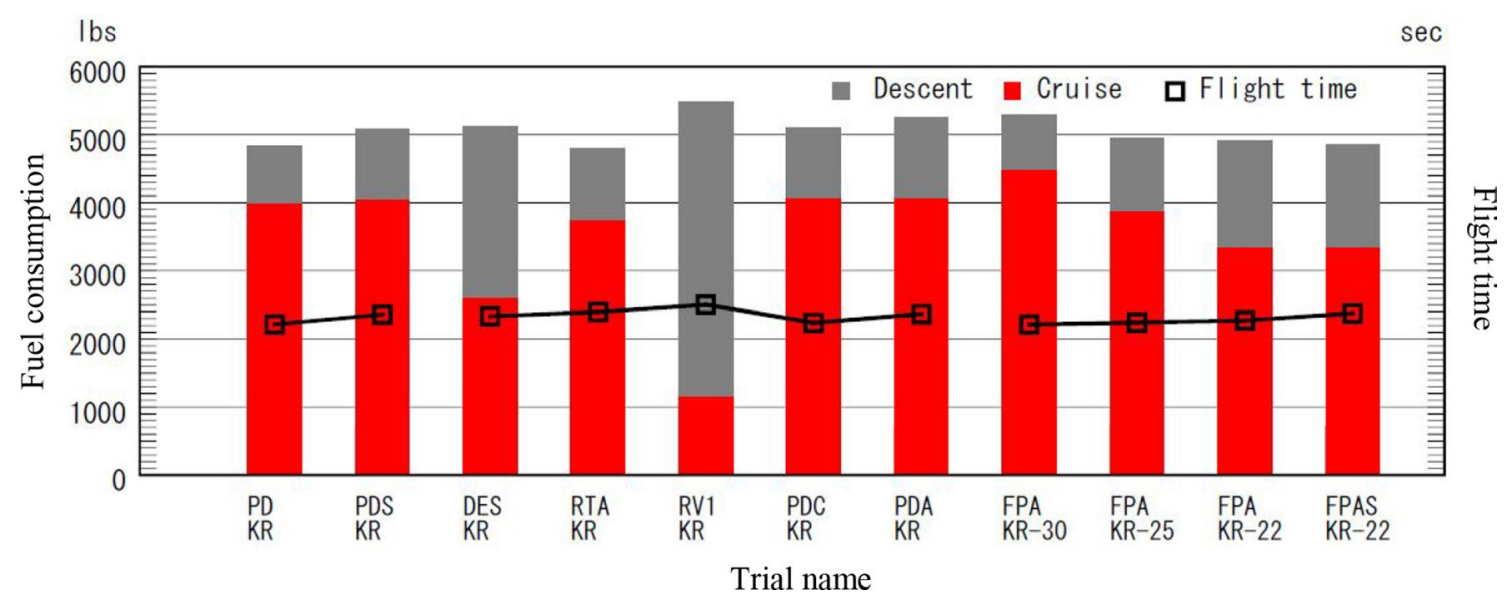

Fig. 19 Fuel consumption and flight times (the $y$ axes have the same scale)

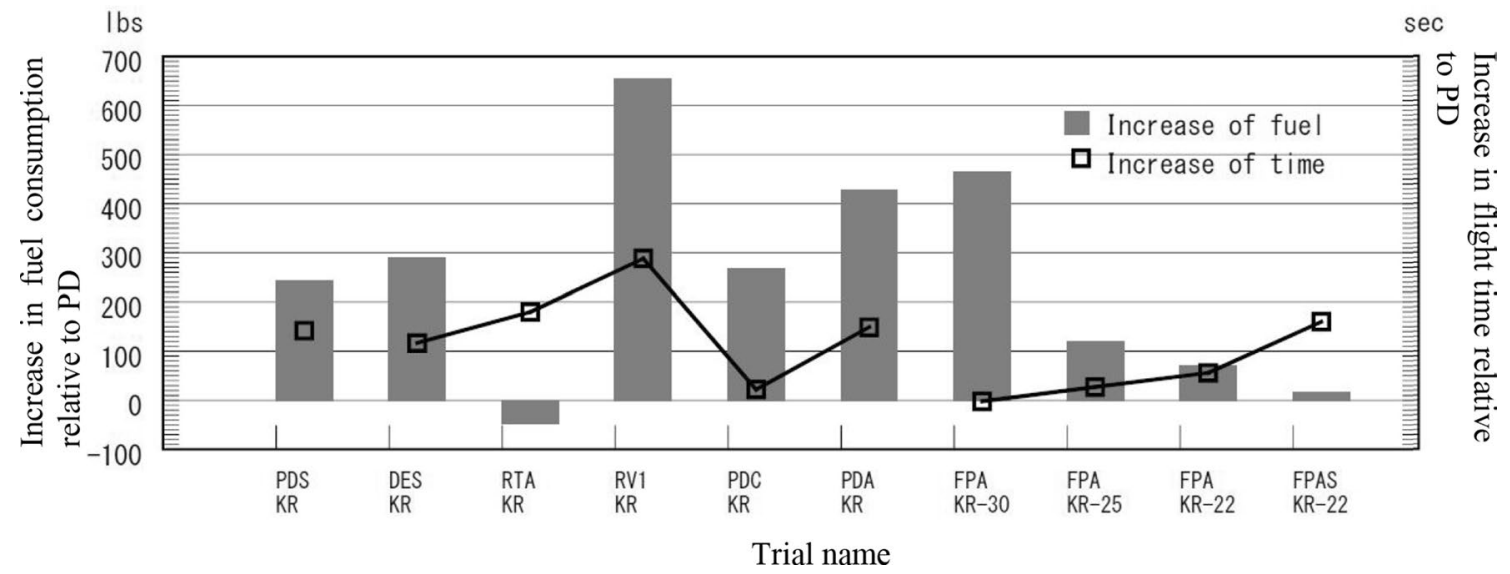

Fig. 20 Increase in fuel consumption and flight times relative to PD (the $y$ axes have the same scale)

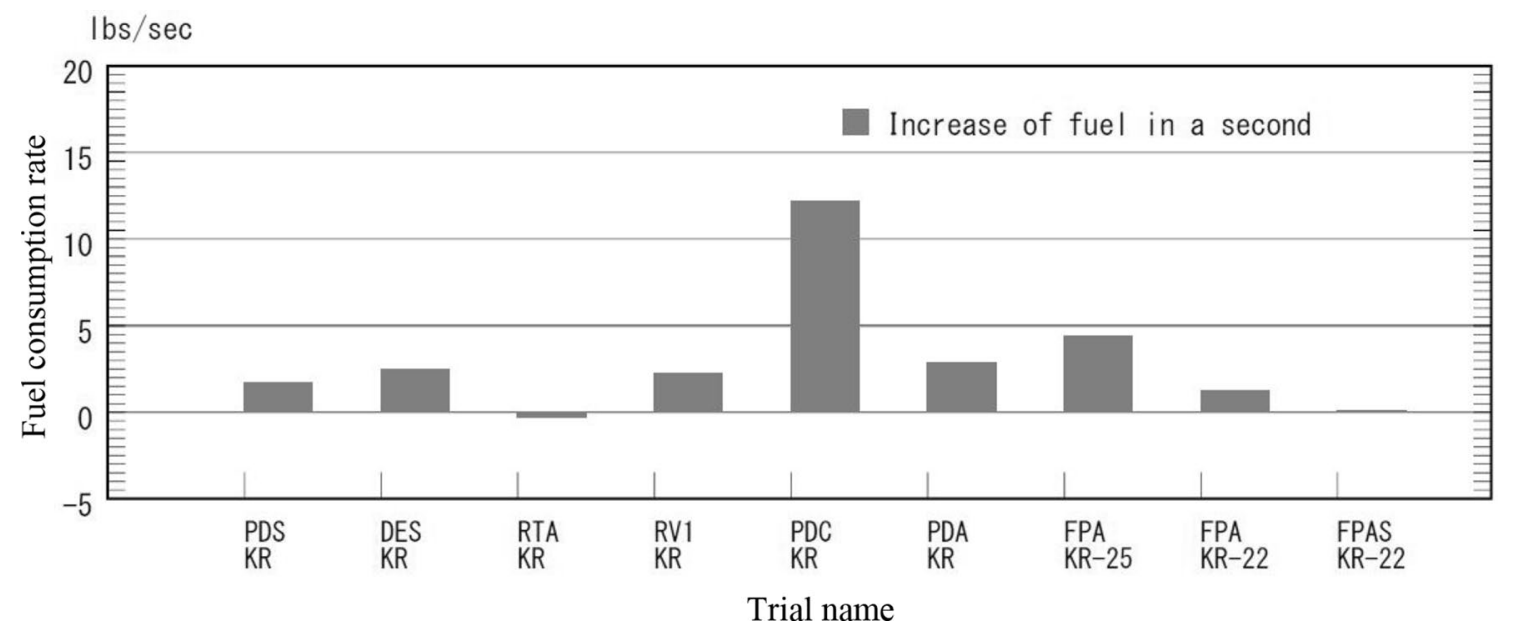

Fig. 21 Fuel consumption rate increase 
aircraft speed during descent. As a result, the arrival was delayed by $180 \mathrm{~s}$ in the PD trial, even though the pilot input only a 2-min delay. It is speculated that better performance of the speed control is required to achieve the assigned time spacing in arrival operations. Applying FIM speed control during FPA descent is one of the options for achieving both arrival time management and fuel efficiency in the future.

\section{Discussion}

Energy-saving air traffic arrival operations have been extensively studied over the past two decades. There are two conventional mainstream CDO concepts for achieving environmentally friendly arrivals. One is the effort to achieve PD, to allow aircraft to descend smoothly at idle thrust. Many research groups have developed automated systems that improve the accuracy of predicting aircraft trajectory during PD and thus control the arrival time, using trajectory prediction tools on the ground [3, 20-23], or airborne [24-29]. Clarke et al. [3] and Coopenbarger et al. [21] proposed approaches that enable PD constrained with altitude and speed restrictions under oceanic airspace conditions. Coppenbarger et al. [20,21] developed decision support tools for air traffic controllers by integrating advanced air and ground automation through digital datalinks. Although the ground-based trajectory prediction achieved reasonable accuracy levels on predicting the time of arrival, it has not achieved sufficient accuracy in predicting the vertical trajectories of PD flights [30]. Stell et al. [31] applied regression analysis and determined the feasibility of modeling the position where the PD aircraft begins its descent. This method requires observation data on the order of 10,000 data points to achieve reasonable prediction levels in the analysis, for each aircraft type and arrival airport. OsegueraLohr et al. [27] investigated energy-saving flight procedures using conventional transport-category automation through a busy terminal area. The obtained analytical results indicated that understanding the FMS behavior was key to predict the PD trajectory. Williams et al. [28, 29] suggested that a key component of flight guidance was a real-time display of energy error relative to the predicted flight path, and evaluated the proposed guidance approach integrated with conventional FMS via a high-fidelity flight simulation. De Jong et al. [32] proposed flight control laws that allow fullidle descents without using thrust and/or speed brakes and including time constraints. Although the above methods aim at offering highly advanced technical solutions to achieve PD with ideal fuel-saving flight figures, they require the implementation of new automated controls and/or advisory systems in the fundamental components of the ground ATM system and/or the aircraft FMS. To foster the implementation of new avionics systems, it is important to minimize the required airline investment; economic constraints will limit the applicability of these control laws if they require the retrofit of current FMS. Additionally, increasing the automation functions of the ground ATM systems does not guarantee their worldwide implementation, given that each nation has their own ground ATM components, which have typically been developed according to their national plans. Therefore, this study takes a different approach to reach a potential solution to the increase of air traffic in Asia within the next decade: implement CDO by applying FPA descent; this approach could be implemented without any retrofits to the fundamental components already included in the current airborne and ground systems.

Considering this implementation, we note the existence of three different technical levels: first, flight-chart design to support FPA descent operations, and pilot-ATCo voice communication procedures. The flight-chart sets are primarily designed for improving the ATCos' prediction of the aircraft vertical paths. These charts must also support the pilots' decision concerning FPA selection and onboard CDU inputs. Updated pilot-ATCo voice procedures are also required (and must be designed) for initialization of the FPA descent. A second technical level is the suggested development of stand-alone applications for tablet devices to support both ATCos and pilots when choosing the optimum FPA values and speed profiles considering precise wind information. Although FPA descent is applicable without any automation support, these tools would replace a part of the heuristicbased intellectual tasks of ATCos and pilots by optimization methods that would select the optimal FPA vertical path complying with the assigned time of arrival while minimizing fuel consumption. The use of stand-alone tablet devices avoids retrofits of any fundamental components in the current airborne and ground systems. Third, the introduction of datalink technology to replace pilot-ATCo voice communications. Datalink technology is the key to achieve fourdimensional trajectory-based operation (4DTBO), in which aircraft fly to the maximum possible extent on user-preferred trajectories defined by time (speed), latitude, longitude, and altitude. The infrastructure, procedures, and regulations to enable the 4DTBO concept are planned to be implement around 2030. FPA descent is one of the 4DTBO approaches, which supports environment-friendly ATM. Further studies on FPA descent implementation will be discussed in the authors' follow-up future work.

Ongoing studies have been applying optimization methods to select the optimal FPA vertical path that complies with the assigned time of arrival while minimizing fuel consumption. The effectiveness of the proposed optimization methods will be evaluated via numerical simulation considering wind uncertainties and geometric constraints. To obtain the initial time spacing of arrivals on mixed aircraft streams, arrival manager (AMAN) systems have 
been implemented in air traffic control centers as advisory systems for air traffic controllers, to support arrival scheduling covering en-route and terminal airspace. The design and implementation of FPA descent will take maximum advantage of the AMAN systems, considering flight envelope restrictions such as minimum and maximum speed (which depend on the aircraft type). The application development should consider non-ISA conditions in the environmental assumptions. Human-in-the-loop simulation experiments will also be carried out to validate the proposed framework.

\section{Conclusion}

This paper discussed the feasibility of the proposed FPA descent for large passenger aircraft, based on a series of full flight simulator experiments. A total of 30 trials were carried out to simulate B777-200 and B787-800 arrival operations at the Tokyo and Kansai International Airports.

To conclude, we emphasize that this paper clarified two questions: first, the proposed FPA descent was shown to be feasible for B777-200 and B787-8 wide-body jet passenger aircraft equipped with current FMS, through pilot intervention. Both the experimental results and the comments obtained from the involved pilots indicate that FPA descent is operationally feasible if the FPA values are selected properly (shallower than $2.5^{\circ}$, under the experimental assumptions in this paper). Secondly, FPA descent could achieve fuel-saving arrival operations (as compared with conventional arrival operations). The amount of arrival delay could be controlled by selection of the FPA settings and airspeed adjustment. The combination of speed control with FPA descent has the potential to result in significant improvements in fuel and time management efficiency in future operations, when compared with conventional arrival operations: speed control during PD, partial PD, ATCo's radar vectoring, and early descent before the scheduled TOD.

This paper reports feasibility studies of fixed FPA descent plans, incorporating the flight-deck perspective of pilots experienced with the B777-200 and B787-8 aircraft. Future study will extend these tests to a wider variety of aircraft to encourage the near-term implementation of FPA descent.

Acknowledgements We are grateful to Dr. Steve Green and Dr. Gilbert $\mathrm{Wu}$ of the NASA Ames Research Center for the fruitful discussions on FPA descent. Special thanks go to the Japan Civil Aviation Bureau (JCAB) and the Japan Airlines Co. Ltd. (JAL) for providing technical and intellectual support on flight simulator experiments.

Funding This research received funding from the Japan Civil Aviation Bureau (JCAB) through the Collaborative Actions for Renovation of Air Traffic Systems (CARATS).

\section{Compliance with ethical standards}

Conflict of interest The authors declare that they have no conflict of interest.

Open Access This article is distributed under the terms of the Creative Commons Attribution 4.0 International License (http://creativeco mmons.org/licenses/by/4.0/), which permits unrestricted use, distribution, and reproduction in any medium, provided you give appropriate credit to the original author(s) and the source, provide a link to the Creative Commons license, and indicate if changes were made.

\section{References}

1. Japan Aircraft Development Corporation (JADC): Worldwide Market Forecast 2016-2035. http://www.jadc.jp/files/topics/109_ ext_01_en_0.pdf (2017). Accessed 10 Sep 2017

2. International Civil Aviation Organization (ICAO): Continuous descent operations (CDO) manuals. ICAO Doc 9931, AN/476 (2010)

3. Clarke, J.P.B., Brooks, J., Nagle, G., Scacchioli, A., White, W., Liu, S.R.: Optimized profile descent arrivals at Los Angeles International Airport. J. Aircr. 50(2), 360-369 (2013)

4. Wu, M.G., Green, S.M.: Analysis of fixed-flight path angle descents for the efficient descent advisor. NASA/TM-2011$215992(2011)$

5. Wu, M.G., Green, S.M.: Choosing descent flight-path angles for small jets: case study for the JFK airport. In: AIAA Aviation Technology, Integration, and Operations Conference, AIAA 2013-4250, Los Angeles, CA, USA (2013)

6. Wu, M.G., Green, S.M., Jones, J.: Strategies for choosing descent flight-path angles for small jets. J. Aircr. 52(3), 847-866 (2015)

7. Clarke, J.P.B.: Systems analysis of noise abatement procedures enabled by advanced flight guidance technology. J. Aircr. 37(2), 266-273 (2000)

8. Sopjes, R., de Jong, P.M.A., Borst, C., van Paassen, M.M., Mulder, M.: Continuous descent approaches with variable flightpath angles under time constraints. In: AIAA Guidance, Navigation, and Control Conference, AIAA 2011-6219, Portland, OR, USA (2011)

9. Itoh, E., Uejima, K.: Applying flight-deck interval management based continuous descent operation for arrival air traffic to Tokyo International Airport. ATM Semin. 2013 (2013)

10. Itoh, E., Uejima, K., Kakichi, Y., Suzuki, S.: Modeling and simulation study on airborne-based energy saving arrivals to Tokyo International Airport. In: AIAA Guidance, Navigation, and Control Conference, AIAA 2013-4779, Boston, MA, USA (2013)

11. Itoh, E., Wickramasinghe, N.K., Hirabayashi, H., Uejima, K., Fukushima, S.: Analyzing feasibility of continuous descent operation following fixed-flight path angle from oceanic route to Tokyo International Airport. In: AIAA Modeling and Simulation Technologies Conference, AIAA SciTech 2016-0168, Washington, DC, USA (2016)

12. RTCA: DO-317A minimum operational performance standards (MOPS) for aircraft surveillance applications (ASA) system (2011)

13. RTCA: DO-328 safety, performance and interoperability requirements document for airborne spacing-flight deck interval management (ASPA-FIM) (2011)

14. Thipphavong, J., et al.: Evaluation of the controller-managed spacing tools, flight-deck interval management and terminal area 
metering capabilities for the ATM technology Demonstration \#1. ATM Semin. 2013, 10-13 (2013)

15. Baxley, B., et al.: Air traffic management technology demonstration-1 concept of operations (ATD-1 ConOps), Version 2.0. NASA TM-2013-218040 (2013)

16. Itoh, E., Fukushima, S., Hirabayashi, H., Wickramasinghe, N.K.: Simulation evaluation on fixed-flight path angle descent (Written in Japanese). J. Jpn. Soc. Aeronaut. Sp. Sci. 64(1), 50-57 (2016)

17. Ministry of Land, Infrastructure, Transport, and Tourism: AIS JAPAN, Japan Aeronautical Information Service. https://aisjapan. mlit.go.jp/Login.do (2017). Accessed 10 Sep 2017

18. Kyoto University: Index of /arch/jmadata/data/gpv/original. http://database.rish.kyoto-u.ac.jp/arch/jmadata/data/gpv/original/ (2017). Accessed 10 Sep 2017

19. Van der Geest, P.: The AMAAI modeling toolset for the analysis of in-trail following dynamics, deliverable D2: description and user guide. NLR-CR-2002-112 (2002)

20. Coopenbarger, R.A., Lanier, R., Sweet, D.N., Dorsky, S.: Design and development of the en route descent advisor (EDA) for conflict-free arrival metering. In: AIAA Guidance, Navigation, and Control Conference, AIAA Paper 2004-4875 (2004)

21. Coppenbarger, R.A., Mead, R.W., Sweet, D.N.: Field evaluation of the tailored arrivals concept for Datalink-enabled continuous descent approach. J. Aircr. 46(4), 1200-1209 (2009)

22. Kaiser, M., Schultz, M., Fricke, H.: Automated 4D descent path optimization using the enhanced trajectory prediction model (ETPM). In: Proceedings of the 5th International Conference on Research in Air Transportation (ICRAT 2012), pp. 1-8 (2012)

23. Miquel, T., Manzoni, H., Legrand, F., Martin, D., Millischer, M.: 4D green approach trajectory: illustrative assessment on toulouse approach. In: AIAA Guidance, Navigation, and Control Conference, AIAA Paper 2010-8456 (2010)
24. De Prins, J.L., Ledesma, R.G.: Towards time-based continuous descent operations with mixed 4D FMS equipage. In: 11th AIAA Aviation Technology, Integration and Operations (ATIO) Conference, AIAA Paper 2011-7018 (2011)

25. Garrido-Lopez, D., D’Alto, L., Ledesma, R.G.: A novel fourdimensional guidance for continuous descent approaches. In: Proceedings of the 28th Digital Avionics Systems Conference, IEEE, Paper 6.E.1 (2009)

26. Klooster, J.K., Wickman, K.D., Bleeker, O.F.: 4D trajectory and time-of-arrival control to enable continuous descent arrivals. In: AIAA Guidance, Navigation and Control Conference, AIAA Paper 2008-7402 (2008)

27. Oseguera-Lohr, R.M., Williams, D.H., Lewis, E.T.: Crew procedures for continuous descent arrivals using conventional guidance. NASA/TM-2007-214538 (2007)

28. Williams, D.H., Oseguera-Lohr, R.M., Lewis, E.T.: Design and testing of a low noise flight guidance concept. NASA/TM-2004213516 (2004)

29. Williams, D.H., Oseguera-Lohr, R.M., Lewis, E.T.: Energy navigation: simulation evaluation and benefit analysis. NASA TP-2011-217167 (2011)

30. Stell, L.: Prediction of top of descent location for idle-thrust descents. In: 9th USA/Europe Air Traffic Management R\&D Seminar, Berlin, Germany (2011)

31. Stell, L., Bronsvoort, J., McDonald, G.: Regression analysis of top of descent location for idle-thrust descents. 10th USA/Europe Air Traffic Management R\&D Seminar, Chicago, IL, USA (2013)

32. De Jong, P.M.A., et al.: Time and energy management during descent and approach: batch simulation study. J. Aircr. 52(1), 190-203 (2015) 